PROGRESS IN

POLYMER SCIENCE

Prog. Polym. Sci. 28 (2003) 5-26

www.elsevier.com/locate/ppolysci

\title{
Nanofabrication in polymer matrices
}

\author{
Tianbo Liu ${ }^{\mathrm{a}}$, Christian Burger ${ }^{\mathrm{b}}$, Benjamin Chu ${ }^{\mathrm{b}, *}$ \\ a Brookhaven National Laboratory, Department of Physics, Upton, NY 11973-5000, USA \\ ${ }^{\mathrm{b}}$ Department of Chemistry, State University of New York at Stony Brook, New York, NY 11794-3400, USA
}

Received 22 April 2002; revised 10 June 2002; accepted 12 June 2002

\begin{abstract}
Polymeric systems have played important roles as templates for nanofabrication since they can offer nanotemplates with different morphologies and tunable sizes, can be easily removed after reactions, and can be further modified with different functional groups to enhance the interactions. This review covers recent advances in polymer-assisted fabrication of nanomaterials with emphasis on ordered polymeric nanostructures. Examples could include self-assembled amphiphilic block co-polymers/surfactants, cross-linkable polymers, dendrimers, microemulsions, latex particles, biomacromolecules, electric- or shear-induced structures as templates to fabricate inorganic, organic/inorganic composites and polymeric materials with nanoscale modifications. The phase behavior of block co-polymers in water and the use of templates to form ordered nanostructures are reviewed in detail. Modern physical techniques for nanoscale characterization are briefly discussed. (C) 2002 Elsevier Science Ltd. All rights reserved.
\end{abstract}

Keywords: Nanofabrication; Nanostructures; Templating; Self-assembly; Block co-polymers; Polymer solutions

\section{Contents}

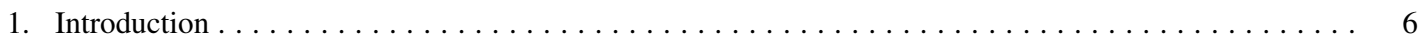

2. Phase behavior of self-assembling systems used as templates $\ldots \ldots \ldots \ldots \ldots \ldots \ldots \ldots \ldots \ldots$

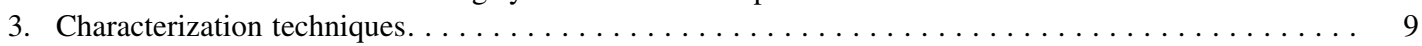

4. Surfactants and amphiphilic block co-polymers as templates $\ldots \ldots \ldots \ldots \ldots \ldots \ldots \ldots \ldots \ldots \ldots \ldots 10$

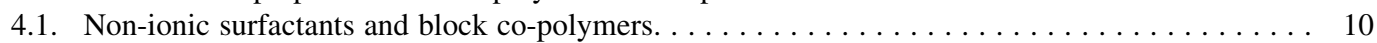

4.2. Ionic surfactants and block co-polymers $\ldots \ldots \ldots \ldots \ldots \ldots \ldots \ldots \ldots \ldots \ldots \ldots \ldots \ldots$

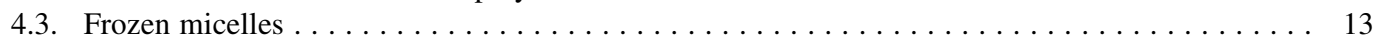

4.4. Cross-linkable co-polymers $\ldots \ldots \ldots \ldots \ldots \ldots \ldots \ldots \ldots \ldots \ldots \ldots \ldots \ldots \ldots \ldots \ldots$

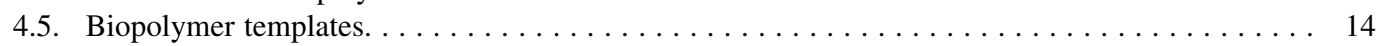

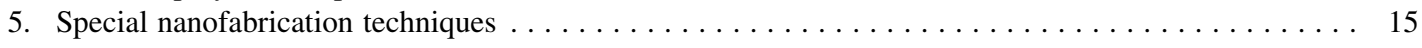

5.1. Functional polymer structures as nanoreactors $\ldots \ldots \ldots \ldots \ldots \ldots \ldots \ldots \ldots \ldots \ldots$

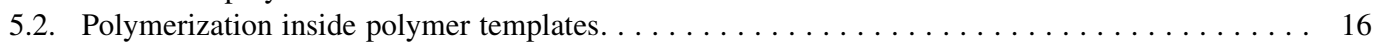

5.3. Surfactant vesicle templates $\ldots \ldots \ldots \ldots \ldots \ldots \ldots \ldots \ldots \ldots \ldots \ldots \ldots \ldots \ldots \ldots \ldots 17$

5.4. Templating based on microemulsions, emulsions and latex particle suspensions $\ldots \ldots \ldots \ldots 17$

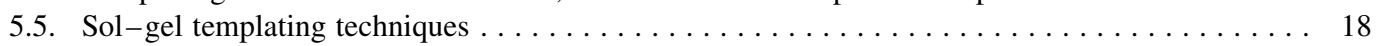

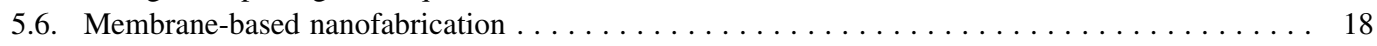

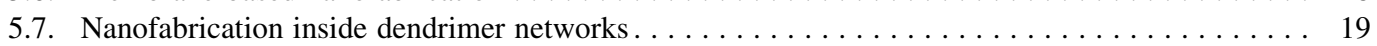

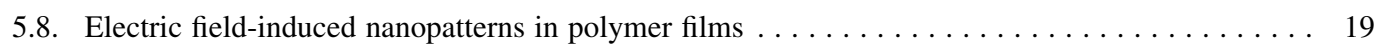

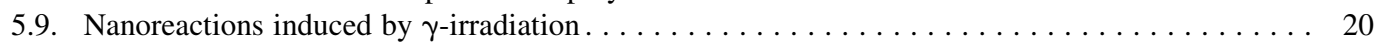

\footnotetext{
* Corresponding author. Tel.: +1-631-632-7928; fax: +1-631-632-6518.

E-mail addresses: bchu@notes.cc.sunysb.edu (B. Chu), liu@bnl.gov (T. Liu), cburger@sunysb.edu (C. Burger).
} 
5.10. Biomimetic synthesis of inorganic nanomaterials and nanocomposites $\ldots \ldots \ldots \ldots \ldots \ldots$. 20

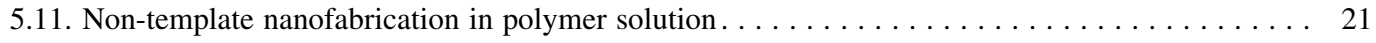

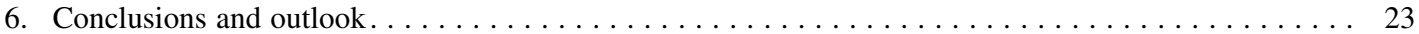

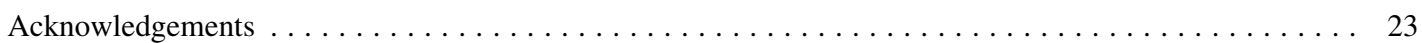

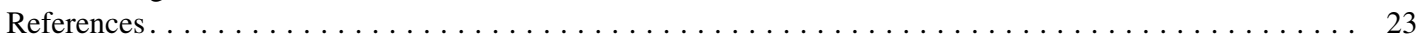

\section{Introduction}

In the emerging and popular field of nanostructured materials, structural manipulations at an atomic, molecular and/or supramolecular length scale are an essential pathway permitting the design of novel materials. Depending on the desired structures and the exploitation of unique properties that emerge at the nanometer scale, there are several approaches to achieve such a goal and, indeed, many ingenious schemes have been devised.

In the fabrication process, the use of organic manipulators (polymers or surfactants) has been particularly fascinating. The organic polymeric materials act primarily as templates, leaving an imprint of the organic presence even after their removal. The fabrication of nanomaterials has become a highly active research area involving scientists in many different fields, e.g. physics, chemistry, biology and materials science and engineering. The inorganic synthesis including biomineralization using intermolecular bonds to act in a co-operative manner in order to construct organized supramolecular systems by selfassembly has been of particular interest. The studied inorganic materials have been extended to semiconductors, silicon-based materials, super-magnetic materials and biomineralized composites (e.g. bone, teeth). A minority component of organic material in ceramics can also toughen brittle microstructures, though at the expense of reduced thermal resistance. New materials with many applications in electronics, catalysis, biotechnology, molecular engineering, and sensory devices can be synthesized.

Polymer systems have always played a crucial role in many nanofabrication processes. With self-organizing materials, including liquid crystals, block co-polymers, hydrogen- and $\pi$-bonded complexes, and, of course, biopolymers, hierarchical structures can be formed. Without doubt, the primary reason for using polymeric systems as templates is that they can form ordered nanoscale structures in bulk or in solution. These ordered nanostructures, represented typically by block co-polymers, microemulsions, polyelectrolyte-surfactant complexes (PSCs) and many natural macromolecules, are tunable over a broad variety of morphologies ranging from discrete micelles to highly symmetric continuous network structures.

The hierarchical structures imply ordering to larger length scales. Sophisticated processing can often be devised to form hierarchical structures with controlled ordering over a range of length scales. The control parameters can include decoration of surfaces with different kinds of chemical groups, creation of surfaces with different geometrical properties (e.g. curvature), and competing interactions that, in combination with molecular architecture, determine the levels of ordering in self-organizing polymeric materials [1]. By combining micromolding, polystyrene sphere templating, and co-operative assembly of inorganic sol-gel species with amphiphilic triblock co-polymers, hierarchically ordered inorganic compounds (e.g. the oxides silica, niobia, and titania) with three-dimensional (3D) structures patterned over multiple length scales were prepared [2].

Further studies on polymeric matrices led to the developments of more refined templating systems, which could be more stable (e.g. cross-linked micelles, frozen micelles), more monodisperse (e.g. latex particles), with better control to tune the template morphologies (e.g. saltinduced morphology changes in ternary surfactant systems), more ordered packings of nanotemplates with higher longrange order (e.g. electric field-induced or shear-induced templating), as well as specialized systems for fabricating specific compounds (e.g. modified polymer chains with functional groups which act as both templates and reagents). These new approaches substantially extended this field in recently years, and they will be our major topics in this review.

Early in 1993, Mann [3] has reviewed studies on molecular tectonics in biomineralization and biomimetic materials chemistry. For controlled synthesis of inorganic and composite materials with higher-order architectures, the strategies involve supramolecular preorganization, interfacial molecular recognition (templating) and cellular processing. Biological mineralization is closely coupled with the development of finely scaled, highly controlled inorganic precipitates in an organic matrix.

In the following years, the dramatic development in the field of nanostructured materials led to the production of a special issue in Chemistry of Materials in 1996, edited by Bein and Stucky, where 71 mini-reviews focused on different specific aspects with thousands of references were published [4]. Macromolecular systems including surfactants and their complexes in solution, bulk or thin film states functioning mainly as templates, sometimes also as reagents and substrates, were involved. The whole area has been expanding even faster and more broadly since then, with large amounts of research being published every year. Therefore, at this time, it is inappropriate to cover every major topic in this field within only a limited number of pages. Moreover, several in-depth reviews have appeared in recent years which introduced the extensive works in the 
field of fabrication and biomineralization of functional materials (especially inorganic compounds) with nanoscale modifications, as represented by the reviews written by Mann [3], Ying et al. [5], Martin [6], and Stucky and co-workers [7,8]. Many major nanofabrication processes have already been summarized in these reviews and need not be repeated here. We would like to approach the field from a different point of view, focusing at a targeted audience with interests predominantly in polymers, and concentrating on the role of various polymer systems and their nanostructures, such as amphiphilic block co-polymers, surfactants, dendrimers and polyelectrolytes in both bulk and solution states, as well as polymer films, during the nanofabrication processes.

It should be pointed out that an important direction towards nanofabrication, which is usually called 'soft lithography', has become a very popular and powerful technique [9-14]. Developed mainly by Whitesides and co-workers, this technique uses surface imprinting to fabricate small devices or complicated nanostructures by using soft condensed matter (e.g. polydimethylsiloxane, PDMS) as both the template and the final product. It is obviously very difficult to handle extremely small quantities (e.g. nanoliters) at such small length scales (submicrons) by any other technique. Therefore, this approach has been widely accepted as one of the most promising ways to construct nanodevices, such as devices for handling nanoliter quantities of fluids, which could find tremendous applications in broader fields of biology, chemistry and materials science, e.g. in combinatorial analysis or synthesis. However, due to the specific goals of this review, we do not plan to cover this area here but limit our scope to the nanofabrication in bulk systems, solutions and gels.

In the course of this review, we will first discuss the phase behavior of polymer and surfactant systems usable as templates for nanofabrication, Section 2. Following will be an overview over various characterization techniques relevant in the present context, Section 3. In the main part of the review, polymer-based nanofabrication will be investigated depending on the chemical nature of the organic matrix, Section 4, and various special techniques will be reviewed, Section 5 .

\section{Phase behavior of self-assembling systems used as templates}

Many polymer systems have been successfully employed as synthetic templates for the fabrication of nanostructured materials. Among them, the most widely used ones are amphiphilic block co-polymers and their oligomer-sized counterparts, the surfactants [15-17]. They can self-associate into organized structures in a selective solvent, i.e. a solvent selectively good for one part of the molecule (e.g. the head group(s) of a surfactant or the hydrophilic block(s) of a block co-polymer in water) and a poor solvent or non-solvent for the other part (e.g. the organic tail(s) of the surfactant or the hydrophobic blocks(s) of the block co-polymer). The so formed systems include micelles, microemulsions, vesicles, monolayers (on surfaces) and many biologically important systems (e.g. cell membranes). Even for much more complicated selfassembled systems, the solvent-phobicity difference of the blocks or segments usually contributes significantly to the driving force for forming the segregation leading to the ordered nanopatterns.

The self-assembly of block co-polymers into micellar structures occurs when they are dissolved in a selective solvent, with the solvent-phobic blocks forming the core and the solvent-philic blocks forming the corona [15-17]. The formation of spherical micelles with the so-called 'coreshell' morphologies often obeys a close-association mechanism [18] (Fig. 1):

$n \mathrm{~A} \rightarrow(\mathrm{A})_{n}$

The association number of the micelle (the number of polymer chains in one micelle) is about the same for all of the micelles under fixed external conditions, i.e. micelle size distributions typically show a low degree of polydispersity. This holds true even for polydisperse block co-polymers or surfactants, which still minimize their free energy by aggregating into micelles of close to the uniform size. The size of the micellar core is determined by the association number and the amount of other solvent-phobic species incorporated into the core. For triblock co-polymers with two end blocks in a poor or non-solvent, supramolecular formation with open structures that tend to obey an open-association mechanism can occur [18-20] (Fig. 1):

unimer $\rightarrow$ dimer $\rightarrow$ trimer $\rightarrow \cdots$

Under these conditions, broad distributions of the micellar size and mass can be observed. Furthermore, as a function of external conditions such as temperature or solvent composition, micellar shapes other than spherical can be observed, e.g. prolate [21-24] or oblate [25] ellipsoids of revolution.

While the phase behavior of low oligomer-sized surfactants had been studied earlier, that of block co-polymers has drawn much attention since around 1980. The most well-studied polymer/solvent systems are nonionic block co-polymers, especially Pluronics, which are a series of triblock co-polymers containing hydrophilic $\mathrm{E}$ blocks and hydrophobic P or B groups, with E, P, B being polyoxyethylene, polyoxypropylene and polyoxybutylene, respectively, in a mixture of water and an organic solvent (both miscible and immiscible, such as butanol and xylene, respectively). Extensive work has been done by scientists in many countries, such as the research groups at Lund University, Bayreuth University and Ris $\varnothing$ National Laboratory.

One of the most common methods to determine the phase structure of gel-like materials is small-angle X-ray 


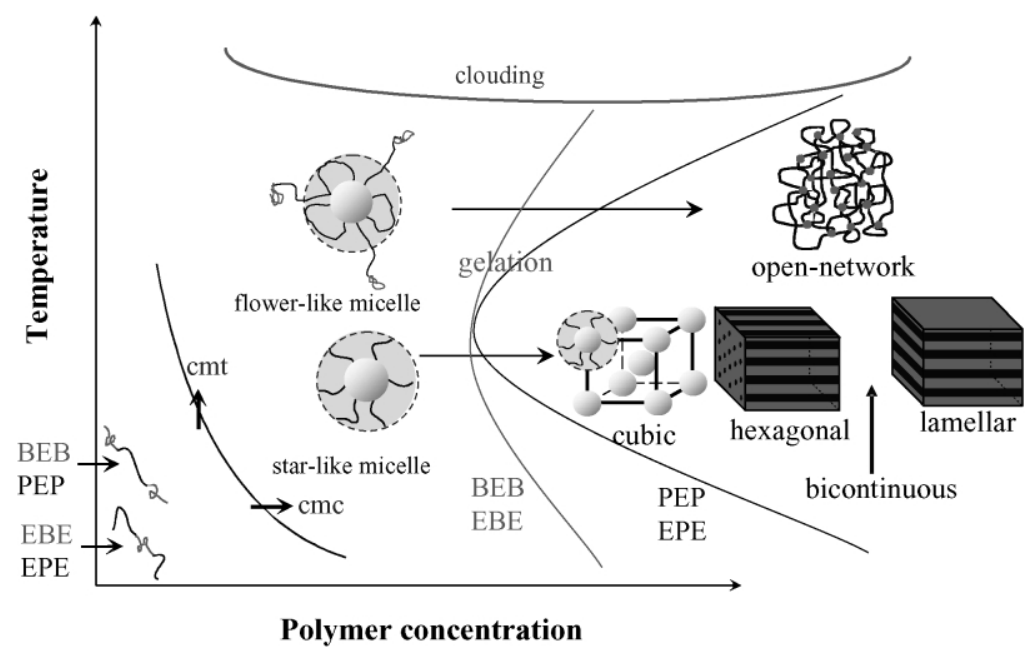

Fig. 1. Schematic phase diagram for the phase behavior of amphiphilic block co-polymers, represented by EBE and BEB type triblock co-polymers in aqueous solution.

scattering (SAXS). In the presence of an ordered periodic super-structure on a nanometer length scale (macrolattice), the SAXS pattern consists of discrete peaks revealing both the symmetry of the structure as well as the size parameters of its unit cell. Electron microscopy studies can provide direct evidence on the morphologies. Visual observation and microscopy under crossed polarizers as well as rheological measurements are also widely used in determining the gel phases.

The phase behavior of block co-polymers in water has been well studied since most of the applications of copolymers are in aqueous solution [17]. The solubility of block co-polymers decreases with increasing temperature and, above a certain temperature, phase separation occurs ('cloud point') [20]. At higher polymer concentrations, the entanglement of the polymer chains in solution leads to the formation of homogeneous, immobile gel-like structures. The first gel-like structure is usually a cubic structure (bodycentered cubic or face-centered cubic, bcc or fcc, respectively), formed by an ordered packing of spherical micelles. At even higher polymer concentrations, the arrangement of the hydrophilic and hydrophobic regions leads to the formation of hexagonal or lamellar structures. Bicontinuous cubic structure could also be observed between the hexagonal and lamellar regions [15-17]. For the flowerlike micelles formed by a block co-polymer in a selective solvent for the middle block, an open network without any ordered structure is generally obtained at high polymer concentrations. A schematic phase diagram is shown in Fig. 1 to demonstrate the general phases and phase transitions of block co-polymers in aqueous solution.

Co-polymer/water/oil ternary phase diagrams can be much more complicated even at a constant temperature [26-32]. Consequently, these systems can provide many more different nanostructures with tunable dimensions by adjusting their composition or block lengths and by using different oils. Lindman and co-workers [29-32] did extensive studies on the phase behavior of Pluronics in the presence of water and xylene. The ternary phase diagram of Pluronic P84 $\left(\mathrm{E}_{19} \mathrm{P}_{44} \mathrm{E}_{19}\right) /$ water/p-xylene studied by Alexandridis et al. [32] at room temperature is reproduced in Fig. 2 where at least nine different phases can be identified: normal micellar solution (oil-in-water), cubic, hexagonal, bicontinuous cubic, reversed micellar solution (water-in-oil), cubic, hexagonal, bicontinuous cubic phases and a lamellar phase. These nine phase classes represent all known possible phases in such a ternary system.

In general, block co-polymer systems can offer various different nanoscale templates such as 3D cubic packings of spherical units, two-dimensional (2D) hexagonal packings of cylindrical units, one-dimensional (1D) periodic lamellar systems, and 3D bicontinuous cubic morphologies. Considering that the total chain length, the block length ratio, the chain architecture and the chemical composition of block co-polymers are all adjustable, the templates can be easily tuned to fit specific requirements. Sometimes, micelles with differing morphologies (e.g. ellipsoids or rods) can also be achieved by choosing a suitable combination of block length and solvent quality. Therefore, it is not surprising that block co-polymers have been heavily applied in nanofabrication processes.

For example, the 1D, 2D and 3D periodic structures of block co-polymers have been used extensively for the fabrication of photonic crystals [33-35]. Photonic crystals are ordered super-structured materials consisting of domains with different optical density. Completely removing one domain naturally leads to the highest optical density contrast. The periodic spacings of photonic crystals are of the same order of magnitude as the wavelength of visible light, i.e. several hundreds of nanometer, giving these materials their unique optical properties and their name. Due to their comparatively large length scales, photonic crystals 


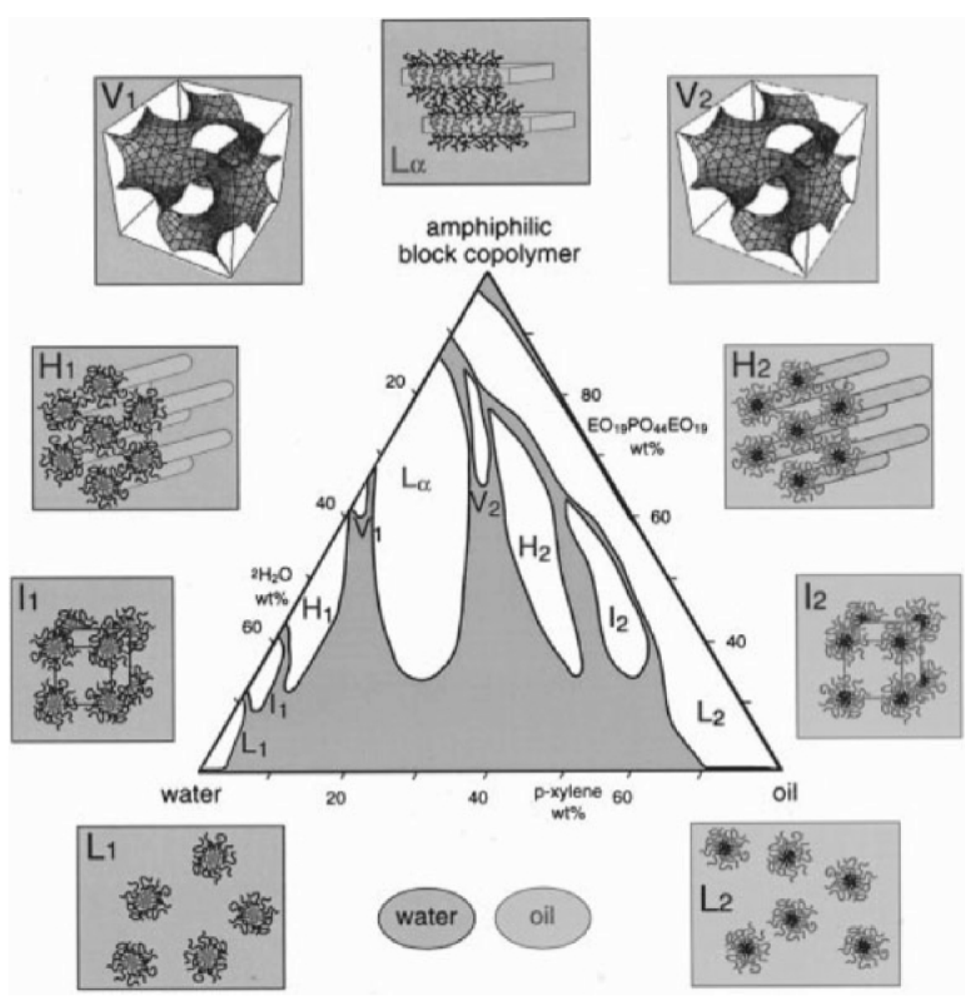

Fig. 2. Ternary phase diagram of Pluronic $\mathrm{P} 84\left(\mathrm{E}_{19} \mathrm{P}_{44} \mathrm{E}_{19}\right) /$ water/p-xylene at room temperature. Nine different phases can be identified: normal (oil-in-water) micellar solution $\mathrm{L}_{1}$, cubic $\mathrm{I}_{1}$, hexagonal $\mathrm{H}_{1}$, bicontinuous cubic $\mathrm{V}_{1}$, reversed (water-in-oil) micellar solution $\mathrm{L}_{2}$, cubic $\mathrm{I}_{2}$, hexagonal $\mathrm{H}_{2}$, bicontinuous cubic $\mathrm{V}_{2}$ phases, and a lamellar phase $\mathrm{L}_{\alpha}$ (Reproduced with permission from Langmuir 1998;14(10):2627. (C) 1998 American Chemical Society [32]).

range at the border between nanostructures and microstructures. In addition to the use of liquid-crystalline blocks, Thomas and collaborators [36-43] have also explored the supramolecular formation from more complex molecular architectures. These include three-miktoarm star terpolymers [38], comb-coil diblock co-polymers [42] and linear tetrablocks and inverse star-blocks [43].

It should also be noted that the formation of supramolecular structures could be affected by the fabrication processes such as thermal annealing [44], solvent swelling [45], and by the use of rheological means [46,47].

Some other polymeric systems have also proven to be useful for nanofabrication. Polymer latexes or vesicles in solution, as well as microemulsions and emulsions [48-51] can provide well-defined environments with confined geometries, typically spherical in nature, that can be used as templates. On the contrary, the situation in block co-polymer solutions discussed above, these templates usually produce single particles ('colloids' in the classical sense) instead of forming continuous structures with ordered packings. Furthermore, these systems can provide much larger templates (on submicron to micron length scales) than block co-polymer solutions. The formation and stabilization of vesicles or emulsions can be achieved by choosing suitable surfactants or amphiphilic block co-polymers under defined conditions. Certain special polymers, e.g. dendrimers or some modified block/graft co-polymer micelles, offer unique microenvironments ('nanoreactors') that can confine the growth of nanoparticles in solution, so that comparatively uniform nanoparticles are produced [52-58], see Section 5.7.

An extreme degree of control over structural parameters is offered by PSCs, enhancing the ability of polymers to self-organize with electrostatic interactions. The combination of electrostatic interactions and a selection of perfectly monodisperse oligomer-sized surfactants generally leads to much higher degrees of long-range order than what is typically observed in amphiphilic block co-polymers, resulting in a wealth of different morphologies potentially usable as templates or confined reaction environments [59].

\section{Characterization techniques}

The very rich structures of polymer matrices and the subsequent formation of nanostructured materials often require an extensive range of physical techniques to characterize the complex structures over a range of length 
scales from molecular dimensions to micron size scales. These physical techniques include various forms of microscopy to observe structures in real space, of scattering to observe structures in reciprocal space, and of spectroscopy to observe structures and interactions over molecular dimensions. They cover a broader range than those typically encountered in a specific discipline. Thus, a brief outline is presented in this review. The following widely applied experimental techniques have been used to characterize supramolecular structures:

(1) Microscopic techniques

(a) Optical microscopy (including visual observation for sufficiently large species): Information about vesicle size and surface textures, when the length scales reach micron sizes (of the order of the wavelength of visible light).

Polarization microscopy: Surface textures of materials with anisotropic domain structures, e.g. liquid crystals.

(b) Electron microscopy, including scanning transmission electron microscopy and transmission electron microscopy (TEM): Size and shape of self-assembled systems including bicontinuous morphologies. May require (kryo-) microtoming, staining, or replica techniques.

(c) Atomic force microscopy: Micelle size and shape, especially of systems collapsed onto a surface after solvent removal.

(2) Scattering techniques

(a) Static light scattering: Molecular weight $\left(M_{\mathrm{W}}\right)$ and radius of gyration of macromolecules in solution or particles in suspension (Zimm plot). Parameters can be measured as a function of temperature. Pressure becomes an additional easily adjustable variable if the solvent is a super-critical fluid [60].

(b) Dynamic light scattering: Hydrodynamic radius distribution of macromolecules in solution or particles in suspension as a function of concentration.

(c) SAXS including synchrotron SAXS: Identification, size and shape of micelles, specific ordered micelle packings, lamellar, cylindrical or bicontinuous morphologies. Measurements can be carried out as a function of temperature, concentration and/or other parameters, thereby allowing the determination of phase diagrams.

(d) Small-angle neutron scattering: Similar to SAXS, but allows special investigations due to contrast variation by deuteration.

(3) Spectroscopic techniques

(a) Nuclear magnetic resonance (NMR): Local environment, diffusion and mobility properties. Pulsed-gradient spin-echo NMR (PGSE-NMR): Self-diffusion coefficient and hydrodynamic radius. (b) Fourier transform infrared (FTIR) and Raman spectroscopy: Identification of chemical bonds and their local chemical environments.

(c) UV-VIS: Electronic properties, chromophores.

(4) Chromatographic techniques

(a) Gel permeation chromatography (GPC): Molecular weight distributions, fractioning. Can be combined with other spectroscopic or scattering techniques used as detectors for the eluate.

(b) Electrophoresis: Electrophoretic mobility of charged species. Fluorescent labeling through laser-induced fluorescence detection.

(5) Macroscopic properties

(a) Rheology, including viscosimetry: hydrodynamic volume of particles, e.g. micelles in dilute solution.

(b) Calorimetry: Thermal stability of self-assembled systems.

(6) Other techniques

(a) Ellipsometry: Shape of self-assembled systems or particles.

(b) Transient electric birefringence: Rotational diffusion coefficient of anisotropic particles.

(c) Mass spectroscopy, time-of-flight methods: Particle weight and composition.

\section{Surfactants and amphiphilic block co-polymers as templates}

\subsection{Non-ionic surfactants and block co-polymers}

Non-ionic organic amphiphiles and amphiphilic block co-polymers in selective solvents can have very rich phase diagrams, including lamellar and cylindrical as well as disconnected spherical or connected bicontinuous cubic ordered assemblies. The nanostructured amphiphile-solvent mesophase provides an interesting environment for the nucleation and growth of inorganic crystalline structures.

The nanofabrication procedure usually starts with a self-assembled block co-polymer system at high polymer concentration (i.e. in the gel state). Subsequently, inorganic reagents are added to the system and are automatically distributed into their favored environment. For example, water-soluble salts will only populate the hydrophilic regions. Under certain external conditions, chemical reaction can occur in these specific regions and produce stable products, which may be insoluble in the original solvent and, therefore, migrate into their new favored environments. This kind of nanofabrication can have a very peculiar morphology on a nanometer scale, such as nanotubes, nanospheres or nanocavities [3].

The use of surfactants and amphiphilic block co-polymers is actively being pursued by research teams in UC Santa Barbara [61-67], the Max Planck Institute in Golm [68-73], and many others [74-78]. The rich variety 
of morphologies from such self-assembled supramolecular systems offers great potential to construct new materials. It is recognized that many templates use surfactants or/and block co-polymers, whether synthetic or natural, as essential ingredients to achieve self-assembled ordered nanostructures. It should also be noted that many different techniques have been used to organize inorganic nanocrystals, including colloidal crystallization, multilayer casting or deposition, molecular cross-linking, and the use of complementary interactions.

An important early example of using block co-polymer or surfactant matrices for nanofabrication was given by scientists at Mobil Research and Development Corporation in 1992 [79,80]. They used self-associated surfactants as templates to synthesize mesoporous silicate (or aluminosilicate) molecular sieves (M41S) with well-defined pore sizes between 15 and $100 \AA$, much larger than the pore sizes of traditional zeolites. The silicates/aluminosilicates form inorganic walls between ordered surfactant micelles. The organic template material can be removed after reaction simply by calcinations at high temperatures. Subsequently, research on M41S and its derivatives developed very fast, and several high quality reviews appeared within just several years [81-88]. Later, the M41S materials themselves were used as templates (or nanoreactors) to further grow advanced inorganic nanomaterials such as pure metal nanowires $[89,90]$.

Another early example was given by Stupp and co-workers [91]. They used the 2D hexagonal nanostructure formed by cylindrical amphiphilic micelles as a template to synthesize nanotubes of cadmium sulfide (CdS, an important semiconductor), as shown in Fig. 3. CdS was prepared by introducing $\mathrm{H}_{2} \mathrm{~S}$ into a hydrogel containing water-soluble $\mathrm{CdCl}_{2}$ residing only in the hydrophilic region. In the course
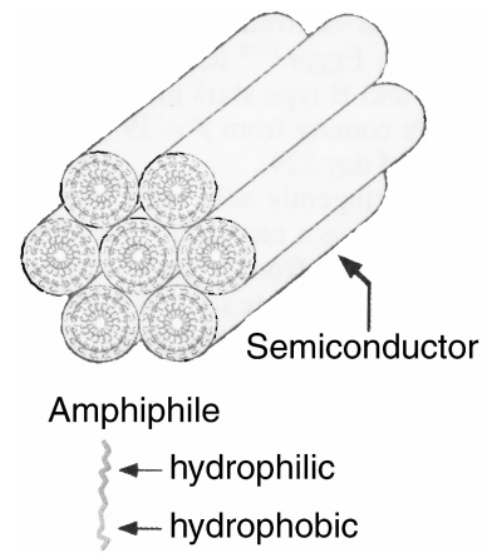

Fig. 3. Two-dimensional hexagonally ordered CdS semiconductor nanocomposite (schematic representation): $\mathrm{CdS}$ has precipitated at the hydrophilic regions of the self-assembled amphiphiles, retaining the hexagonal nanostructure (Reproduced with permission from Nature 1996;380(6572):325. (C) 1996 Macmillan Magazines Limited [91]). of the chemical reaction, the water-insoluble $\mathrm{CdS}$ was accumulated in the hydrophilic region. After removing the polymer matrix by calcination at high temperatures, pure $\mathrm{CdS}$ nanotubes were obtained, maintaining the hexagonal packing as confirmed by SAXS and TEM measurements.

Stucky and co-workers [61] did extensive work to use different Pluronic PEO-PPO-PEO triblock co-polymers as templates to form mesoporous silica. Compared to shortchain surfactants, block co-polymers provided larger and tunable domain sizes that could be used for making silica with larger cavities, an important parameter for molecular sieves. Various mesoporous silica samples with 2D hexagonal packing and having $50-300 \AA$ pores were synthesized. Again, calcination was used after the inorganic reaction to remove all organic material. Both SAXS and TEM, see Fig. 4, confirmed that the final products had hexagonal order on a nanometer length scale. In addition to silica, the Stucky group investigated the preparation of nanomaterials from other inorganic compounds such as the oxides of lead, iron, tungsten, antimony and zinc, using similar techniques [92].

Walsh et al. [93] used bicontinuous water-filled microemulsions as preorganized systems for the fabrication of crystalline calcium phosphate materials with extended reticulated microstructures. This is an example of utilizing sponge-like bicontinuous structures as templates. There are several factors that limit the use of these bicontinuous phases. First, in most phase diagrams, this phase governs only a fairly limited region of the phase diagram, suggesting that it is very sensitive to external parameters. Therefore, it is also difficult to maintain the structure after introducing chemical reactions. Second, contrary to cubic, cylindrical and lamellar phases that all have well-defined long-range order, these bicontinuous sponge phases are less ordered, thereby limiting potential applications of the products. Mann and co-workers successfully found suitable applications for their synthetic macroporous calcium phosphates, suggesting that they could be developed for use as possible implants.

\subsection{Ionic surfactants and block co-polymers}

Compared to non-ionic surfactants and corresponding block co-polymers as templates, the charged electrostatic interaction between a specific inorganic precursor and a surfactant head group (or, in some special cases, a polyelectrolyte) is even more widely applied for nanofabrication, especially for the synthesis of porous silica. Stucky and collaborators [7,92] reported a generalized approach whereby the self-assembly process was controlled by electrostatic interactions between the inorganic ions in solution and the charged surfactant head groups as well as those mediated via the counter ions. Four pathways to the synthesis of mesostructured surfactant-inorganic biphase arrays were depicted. The direct pathways include complex formation between cationic surfactants with inorganic 

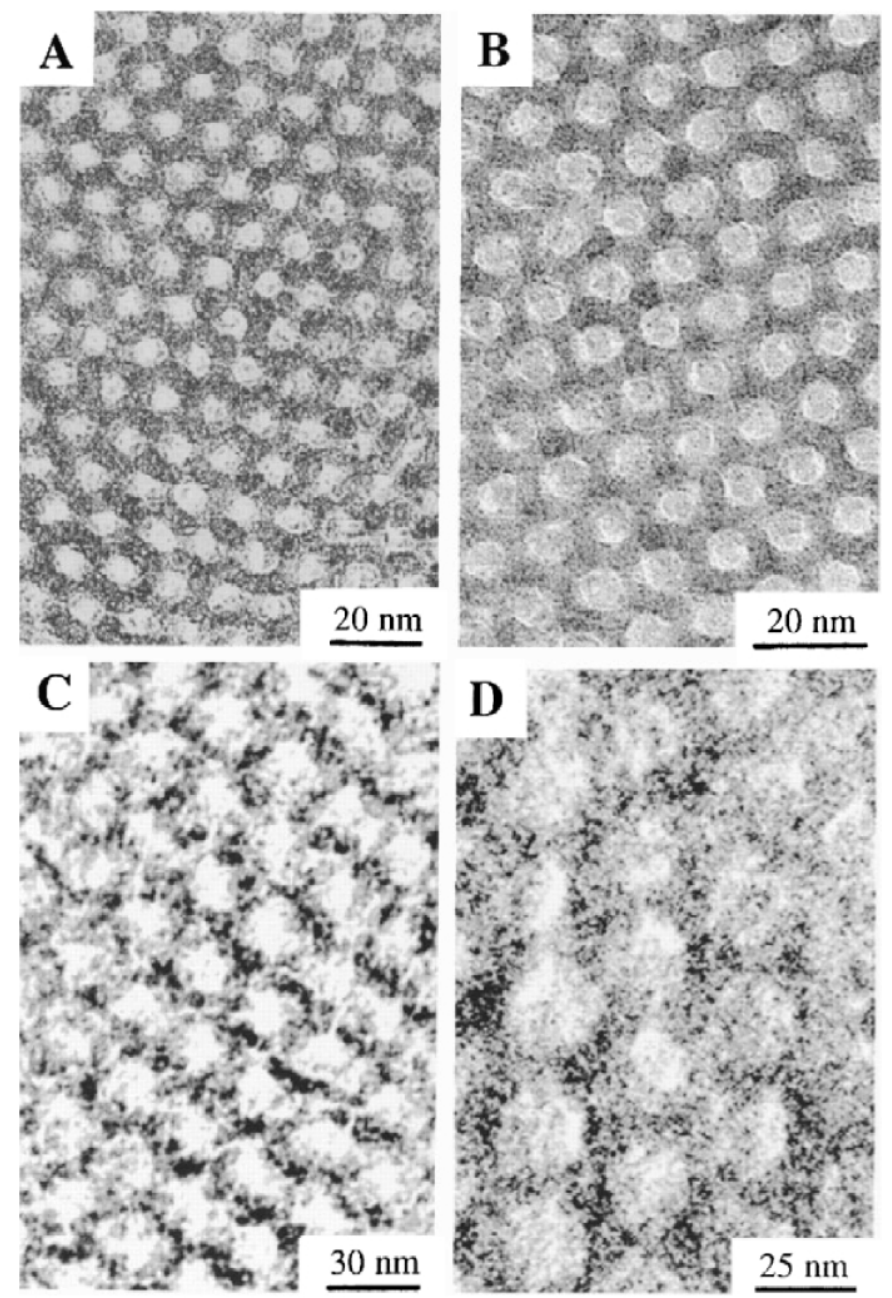

Fig. 4. Transmission electron micrographs of calcinated hexagonal mesoporous silica with different average pore sizes (Å): (A) 60, (B) 89, (C) 200, and (D) 260 (Reproduced with permission from Science 1998;279(5350):548. (C) 1998 American Association for the Advancement of Science [61]).

anions I and anionic surfactants S with inorganic cations, while the mediated pathways involve surfactant and inorganic species having the same charge with interactions mediated via counter ions of the opposite charge. Typical pathways include $\mathrm{I}^{\ominus} \mathrm{S}^{\oplus}, \mathrm{I}^{\oplus} \mathrm{S}^{\ominus}, \mathrm{I}^{\oplus} \mathrm{X}^{\ominus} \mathrm{S}^{\oplus}, \mathrm{I}^{\ominus} \mathrm{M}^{\oplus} \mathrm{S}^{\ominus}, \mathrm{I}^{0} \mathrm{~S}^{0}$, etc. with $\mathrm{X}$ and $\mathrm{M}$ being counter anion and metal cation, respectively. Among the work published by applying these pathways, a large fraction of the work is related to silicate and aluminosilicate mesoporous materials. More information can be readily found. Ying et al. [5] schematically summarized the various types of inorganic compound versus surfactant head group interactions and provided examples, see Fig. 5.

An interesting example was given by Hanabusa and co-workers [94]. By taking advantage of the self-assembly of an amphiphilic polymer, they synthesized long 'macaroni'like $\mathrm{TiO}_{2}$ hollow fibers with potential applications in photovoltaic solar cells, photocatalytic devices and rechargeable lithium ion battery electrodes. They designed a special polymer trans-(1R,2R)-1,2-cyclohexane-di(11aminocarbonylundecylpyridinium)hexafluorophosphate which can self-assemble into rods and interact with $\mathrm{Ti}\left(\mathrm{OCH}\left(\mathrm{CH}_{2}\right)_{4}\right.$ through charge interactions. $\mathrm{TiO}_{2}$ would grow on the surface of the polymer rods into a hollow rod structure. Scanning electromicrographs (SEM) clearly showed the formation of quite uniform $\mathrm{TiO}_{2}$ hollow fibers with inner diameters in the range 150-600 nm and lengths of about $200 \mu \mathrm{m}$, as shown in Fig. 6. Similar approaches have also been reported by different groups using rod-like biological macromolecules as templates to synthesize hollow, tubular inorganic nanomaterials, which will be introduced in Section 4.5.

Micelles at equilibrium with unimers can change the self-assembly behavior by changing the solvent quality. For 


$$
\begin{aligned}
& \text { a) } \quad I^{\ominus} S^{\oplus} R \\
& I=\mathrm{Si} \\
& S=\text { trimethylammonium } \\
& \text { b) } \quad I^{\oplus} S^{\ominus} R \quad I=\mathrm{Sb} \\
& S=\text { sulfonate } \\
& I=\mathrm{Si} \\
& \text { c) } I^{\oplus} X^{\ominus} S^{\oplus} R \quad X=\mathrm{Cl} \\
& S=\text { trimethylammonium } \\
& I=\mathrm{Al} \\
& \text { d) } \quad I^{\ominus} M^{\oplus} S^{\ominus} R \quad M=\mathrm{Na} \\
& S=\text { phosphate } \\
& \text { e) } \quad I^{0} \cdots S^{0} R \\
& I=\mathrm{Si} \\
& S=\text { amine } \\
& \text { f) } \quad I^{0} \cdots N^{0} R \\
& I=\mathrm{Si} \\
& S=\text { polyethyleneoxide } \\
& \text { g) } \quad I-S R \\
& I=\mathrm{Nb}, \mathrm{Ta} \\
& S=\text { amine }
\end{aligned}
$$

Fig. 5. Overview over the various types of interactions of inorganic atoms/ions with surfactant head groups: (a)-(d) electrostatic, (e) and (f) hydrogen bonding, and ( $\mathrm{g}$ ) covalent ( $\mathrm{R}$ is an alkyl chain) Data used from Ref. [5].

example, in an aqueous solution, the solvent quality changes by adding inorganic salts. It changes further when the inorganic species undergo a chemical reaction. The change of solvent quality will certainly affect the phase behavior of the block co-polymers, by shifting the phase diagram and altering the micellar parameters. This complication could decrease the ability to control the nanostructures by using the intended templates, but also offer opportunities to achieve new phases with desired parameters. The most common factors that affect the original structures of templates can be the solubilization of a large amount of reactants, formation of the products and the change in temperature and in the amount of solvent during the reaction. However, it is clear that to induce morphological changes by changing the above external parameters is very difficult, especially when a specific result is desired. Pileni and his co-workers $[95,96]$ demonstrated this by using the

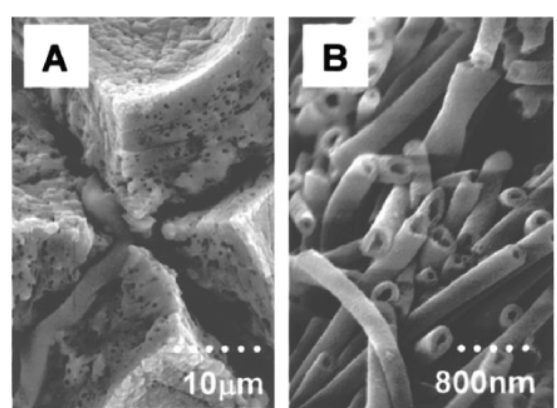

Fig. 6. SEM of calcinated $\mathrm{TiO}_{2}$ hollow fibers prepared under acidic (A) and basic (B) conditions, respectively (Reproduced with permission from Chem Mater 2000;12(6):1523. (C) 2000 American Chemical Society [94]).

same template $\mathrm{Cu}(\mathrm{AOT})_{2}$-isooctane-water ternary system (with AOT being bis(2-ethylhexyl)sulfosuccinate, a doublechained surfactant), but in the presence of different inorganic salts, all at a fixed overall concentration $10^{-3} \mathrm{M}$. The final copper nanoparticles had different shapes, although the structure of the templates did not change drastically with different salts. The authors observed very long $\mathrm{Cu}$ rods upon addition of $\mathrm{NaCl}$ or $\mathrm{KCl}$. In equilibrium with these rods, particles having various sizes and shapes (squares, triangles, etc.) were also observed. Much shorter rods were observed with $\mathrm{NaBr}$ and $\mathrm{KBr}$. $\mathrm{NaHSO}_{3}$ only led to a slight elongation of the particles. The authors discovered certain relationships between the shape change and the socalled Hofmeister series:

$$
\begin{aligned}
\mathrm{SO}_{4}^{2-} & >\mathrm{CO}_{3}^{2-}>\mathrm{HPO}_{4}^{2-}>\mathrm{F}^{-}>\mathrm{Cl}^{-}>\mathrm{Br}^{-}>\mathrm{NO}_{3}^{-} \\
& >\mathrm{I}_{3}^{-}>\mathrm{ClO}_{4}^{-}>\mathrm{SCN}^{-} \\
\mathrm{Na}^{+} & >\mathrm{K}^{+}>\mathrm{Li}^{+}>\mathrm{Rb}^{+}>\mathrm{Cs}^{+}
\end{aligned}
$$

This series is universal because the order of sequence does not depend on the nature of the organic molecules. The authors suggested that the change in the water structure and the rigidity of the template due to the addition of inorganic salts induced changes in the length and in the number of rods produced. This result indicates that the colloidal structure on a microscopic scale can influence the shape of nanocrystals.

\subsection{Frozen micelles}

Using Pluronics as organic templates for inorganic reactions and nanostructure formation, the structural integrity of the nanostructures often cannot be maintained. More robust supramolecular morphologies, such as 'frozen micelles' or cross-linkable co-polymers can be considered as alternative routes.

Instead of Pluronics (EPE type triblock co-polymers), the polyoxypropylene $(\mathrm{P})$ block can be replaced by the more hydrophobic polyoxybutylene (B) or a polystyrene (PS) block. The PS block is essentially insoluble in water. The 
procedure for its micelle formation involves an additional step using a solvent that can dissolve PS and subsequent evaporation of this solvent [97] in the presence of water. Such micelles have a 'frozen' hydrophobic core and can withstand changes in the aqueous solvent quality. The PS and poly(oxyethylene) diblock and triblock co-polymers can interact with suspended PS latex particles in water [98-101]. The adsorption and redistribution of block co-polymers onto the latex surface occurs rapidly upon mixing. Several models have been used to predict the structure and thickness of the adsorbed layer formed by the adsorbed block co-polymer micelles. The presence of large PS latex spheres offers a variation in the overall supramolecular structure. For further examples, see Section 5.4.

\subsection{Cross-linkable co-polymers}

While regular chemically inert block co-polymers have been widely used as templates, an alternative approach of using cross-linkable co-polymers is also very promising. One major advantage of these systems is that they can firmly maintain a certain morphology by chemically linking the co-polymer chains. Therefore, it will not be necessary to worry about the exchange of block co-polymer chains among micelles or in solution. Liu et al. [100] studied polystyrene- $b$-poly (2-cinnamoylethyl methacrylate) (PS- $b$ PCEMA) block co-polymers which could form micelles in a selective solvent. Upon UV irradiation, the PCEMA block can be selectively cross-linked to form star polymers. Depending on the nature of the selective solvent, one region (e.g. either core or shell in a core/shell micelle) of the supramolecular structure can be cross-linked.

The Liu group has synthesized a range of block co-polymers, including PCEMA- $b$-poly(acrylic acid), PCEMA- $b$-polyisoprene, P[CEMA-random-(2-octanoylethyl methacrylate)]-b-poly(acrylic acid), and poly(isoprene)- $b$-PCEMA- $b$-poly(tert-butylacrylate) [102-111]. They took advantage of the cross-linking ability of PCEMA to stabilize the supramolecular structures formed and also characterized the cross-linked micelles by solution and solid state NMR, FTIR, TEM, GPC, and laser light scattering. A range of applications including chemical separations, analysis, and use as drug carriers was proposed. This type of cross-linkable co-polymers that can have morphologies of cylinders and nanofibers, in addition to the spherical micelles, could be used as more stable templates and offer a wider range of alternatives. For inorganic oxides, the polymer templates can be removed by heating, although chemical means for the modification and removal of organic materials exist, see Refs. [104-106,110,111].

\subsection{Biopolymer templates}

Compared to synthetic polymeric templates, biomacromolecular systems can offer templates with monodisperse size distributions and unique charge distributions to fabricate new nanomaterials. Moreover, the study of complexes formed by biomacromolecules and inorganic compounds can offer opportunities to understand certain biological processes such as biomineralization. Many natural materials are well known for their strength and toughness. For example, the 'breakage' energy per unit weight of spider dragline silk is two orders of magnitude greater than that of high tensile-strength steel. The abalone shell, a composite of calcium carbonate plates sandwiched between organic materials, has a fracture resistance about 3000 times higher than a single crystal of calcium carbonate. Biological control can manipulate crystal textures and these textures can be used to perform different functions [112]. An often neglected but very important point of the synthesis of high-strength nanocomposites is to remember that the use of templates represents only one aspect of the fabrication process. For example, for nanocomposites where the organic material is the minority component, incorporation of this organic component is equally critical. Thus, intercalation of proteins inside single-crystal lattices $[113,114]$ or threading of polymer chains through mesoporous materials [115] can be crucial factors in achieving the desired properties for nanostructured materials. An in-depth description of biomineralization processes is beyond the scope of the present review, and the interested reader is referred to the review by Mann [3]. In this section, we concentrate on biological polymers that provide monodisperse and well-defined nanotemplates.

Ghadiri et al. [116-118] presented a simple strategy for the design of artificial membrane ion channels based on the self-assembled cylindrical ring-shaped beta-sheet peptide architecture. The stacks of peptide rings forming the channels displayed good channel-mediated ion-transport activity with rates exceeding 10 million ions per second.

Self-assembled sugar-based lipid galactocerebroside, doped with small amounts of anionic sulfate derivatives, could form tubules or lamellar structures. The supramolecular structures, such as the lipid tubules and phospholipid tubules [119] were used as templates for the crystallization of inorganic oxides [120]. Bacterial S-layers-selfassembled, two-dimensionally ordered films of proteins were used as templates for the in situ nucleation of ordered 2D arrays of CdS nanocrystals of about $5 \mathrm{~nm}$ in size [121].

Peptide tubules have also been used as templates to fabricate nanocrystals. Matsui et al. synthesized carboxylic acid-thiol capped Au nanocrystals on bis $(N$ - $\alpha$-aminoglycylglycine)-1,7-heptane dicarboxylate peptide tubule by using the hydrogen bonding between the amide groups of the tubules and the carboxylic acid groups of the nanocrystals as the driving force of the assembly process, as shown in Fig. 7 [122]. The Au nanocrystal tubule with hollow structures has found application as signal-enhancing cuvettes for Raman spectroscopy, with the Raman scattering of Rhodamine B on the tubule being enhanced by a factor of $10^{5}$. 


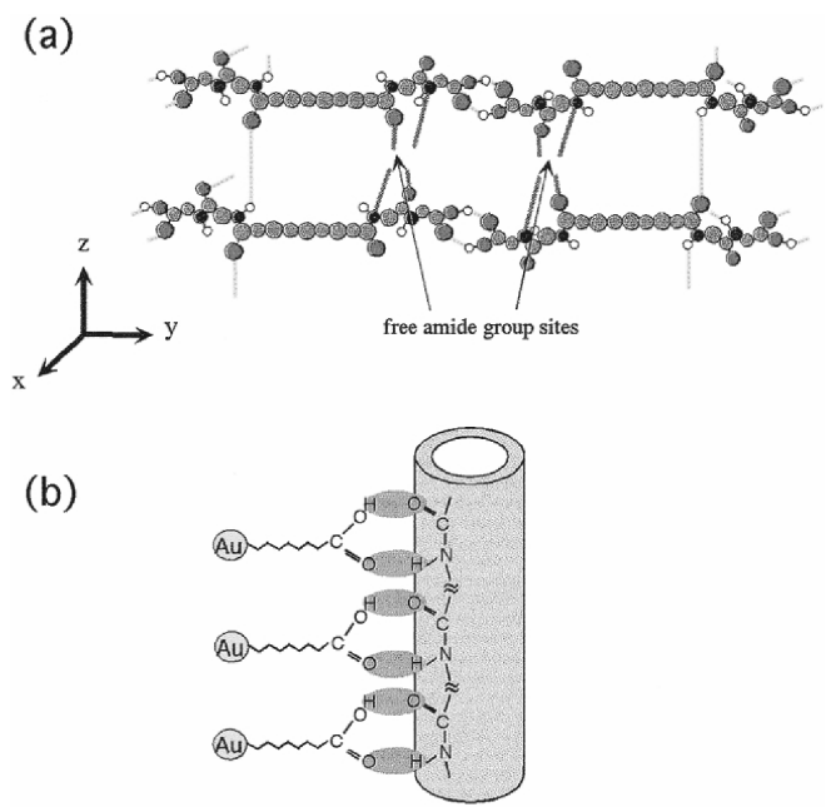

Fig. 7. (a) 'Bolaamphiphile' peptide molecules with free amide groups for hydrogen bond interactions; (b) schematic arrangement of peptide nanotubules and gold nanocrystals (Reproduced with permission from J Phys Chem B 2001;105(9):1683. (c) 2001 American Chemical Society [122]).

\section{Special nanofabrication techniques}

\subsection{Functional polymer structures as nanoreactors}

A segregated microphase in a self-assembled block co-polymer system (e.g. micellar cores) can provide a well-defined nanocompartment that can be used for nanofabrication. Further modifications on the block co-polymer with functional groups can improve the 'solubility' of the reagents in these nanoreactors. This approach had been applied a long time ago for polymer synthesis, known as 'microemulsion polymerization' [123]. Recently, similar but further modified methods designed specifically for inorganic nanomaterials emerged. Cohen and co-workers $[124,125]$ reported the use of microphase-separated poly (methyltetracylododecene-block-2-norbornene-5,6-dicarboxylic)acid (MTD-NORCOOH) block co-polymers as nanoreactors. This technique involved the selective sequencing of metals into the microdomains of a block co-polymer film, and the co-polymer usually contained functional groups, such as carboxylic acid units, to stabilize metal ions. A typical synthesis scheme is shown in Fig. 8. The authors used this method to successfully prepare relatively monodisperse $\mathrm{PbS}$ nanoclusters. One of the major advantages of these nanoreactors is that the loading cycle can be repeated to produce larger clusters. It is also possible to load different metal ions during different cycles, leading to the formation of mixed clusters that may possess novel properties.

The shape transitions of block co-polymer micelles from spherical to cylindrical, rod-like or plate-like have been reported by different groups in the past two decades. The transition usually happens by increasing the fraction of solvent-phobic parts (e.g. increasing the solvent-phobic

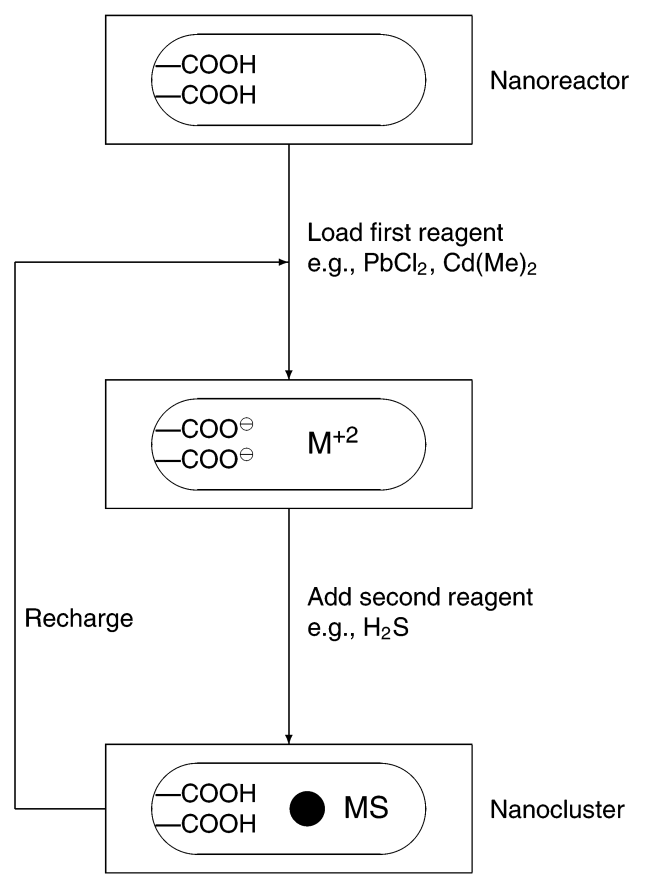

Fig. 8. Universal synthesis scheme for the fabrication of nanoclusters (Reproduced with permission from Chem Mater 1996;8(8):1919. (C) 1996 American Chemical Society [125]). 
block length or adding another immiscible solvent which will stay inside the micellar core) and/or changing the temperature. Typical examples included the 'crew-cut micelles' discovered by Zheng and Eisenberg [126,127] and the water-loaded Pluronic block co-polymer reversed micelles in xylene, studied by our group in the early nineties [128]. The shape transition of micelles (especially of the micellar cores) can be used to synthesize nanoparticles with different shapes. A typical example was provided by the Möller group by loading $\mathrm{HAuCl}_{4}$ into polystyrene-poly(2vinylpyridine) (PS-P2VP) block co-polymer micelles in toluene [129]. The $\mathrm{AuCl}_{4}^{-}$ions interacted with $\mathrm{P} 2 \mathrm{VP}$ blocks inside the micellar cores and could be reduced by $\mathrm{N}_{2} \mathrm{H}_{4}$ to form pure $\mathrm{Au}$ nanoparticles. The micelles acted as nanoreaction vessels and the shape of the micellar cores determined the final shape of gold nanoparticles. The authors used static and dynamic laser light scattering techniques to measure the radius of gyration $R_{\mathrm{g}}$ and the hydrodynamic radius $R_{\mathrm{h}}$ of the micelle-containing gold particles. The ratio $R_{\mathrm{g}} / R_{\mathrm{h}}$ varied as the shape of the nanoparticles changed.

Gin and co-workers [130-132] developed a novel strategy for constructing highly ordered, polymer-based nanocomposites with well-defined architectures by using self-organizing monomers based upon lyotropic liquid crystals. The polymerizable lyotropic liquid crystals were used to form an ordered hexagonal matrix around aqueous solutions containing hydrophilic reagents. The photopolymerization of the liquid crystals locked in the matrix structure. The subsequent initiation of chemical reactions within the hydrophilic domains yielded the final nanomaterials. The authors successfully synthesized well-defined, cylindrical inorganic and organic materials, such as sol-gel silica and polymer-polymer nanocomposites [poly $(p$ phenylenevinylene)]. The dimension of the hexagonal phases could be further tuned by using different transition metal or lanthanide ions as counter ions of the liquid crystal molecules. The major advantage of this technique is that it is able to construct highly ordered, highly controllable bulk, man-made nanoscale architectures that cannot be achieved by conventional approaches. The authors further suggested that these materials are not only useful in fabricating nanocomposites but could also be applied as high-efficiency heterogeneous catalysts.

\subsection{Polymerization inside polymer templates}

In addition to inorganic materials, polymer templates have also been used to create soft matter materials with desired morphologies. The general approach is to first use synthetic matrices to confine the distribution of polymerizable monomers in the system, then trigger the polymerization to get cross-linked polymeric materials with desired nanostructures.

Martin and co-workers [133] investigated the concept of fusing the pores in nanoporous membranes as templates for the synthesis of nanomaterials, including polymeric materials with special structures, such as nanotubules and nanofibrils. They showed that template-synthesized electronically conductive polymer nanofibrils could have electronic conductivities that were orders of magnitude higher than conventional forms of the same polymer. They proposed a model to explain the high conductivity of polypyrrole (Ppy) nanofibrils by pointing out that the fibrils were composed of a thin outer skin of highly oriented polymer with large conjugation length.

As discussed in Section 5.1, Gin and co-workers [130-132] developed an approach of using polymerizable lyotropic liquid crystals containing transition-metal ions as building blocks for fabricating well-defined polymers and nanocomposites with hexagonal architecture. Another interesting work was recently reported by Kim and co-workers [134]. They synthesized a special nanoporous polymer with hexagonal channels from supramolecular diskotic liquid crystal. The template was a complex formed by a benzotri(imidazole) core and three polymerizable alkoxybenzoic acid through hydrogen-bonding interactions. The complex was used as a template during the polymerization of acrylate moieties. After the reaction, the template would be removed so that the cross-linked polyacrylate material with a hexagonal columnar structure remained with an average pore size of about $1 \mathrm{~nm}$. The morphological evolution of the hexagonal structure had been tracked by $\mathrm{X}$-ray diffraction and UV/VIS spectroscopy. The hollow channels could be refilled by reverse chemical reactions. The new nanomaterial was expected to find applications in molecular recognition, separation, catalysis and synthesis of nanocomposites. The preliminary gas permeability measurements showed that for a membrane of their final product, the $\mathrm{N}_{2}$ gas permeability constant was about four orders of magnitude higher than that for low-density polyethylene.

An important approach to fabricate hollow polymeric nanospheres is to use the bilayer structure of existing vesicles. The vesicles formed by cationic or anionic surfactants (or their mixtures) in aqueous solutions contain bilayer structures with a hydrophobic region, which can be used to accumulate and stabilize hydrophobic monomers such as styrene, alkylacrylates or divinyl benzene. The polymerization will occur in the confined environment, very similar to the situation in traditional microemulsion polymerization. The final products are usually polydisperse polymeric hollow spheres, with overall diameters only depending on the size of the vesicles, but not related to the nature of the monomers. Extensive work has been done by Meier and co-workers [135-137]. The application of vesicles as templates deserves further exploration.

Antonietti et al. [71] polymerized acrylamide and other hydrophilic monomers inside templates formed from nonionic surfactants to produce porous gels with variable pore architectures and size ranges up to $1 \mu \mathrm{m}$, investigating the dependence of the structural parameters on the type and 
concentration of the monomer and the surfactant, on the cross-linker density, and on other parameters. Various aspects of the synthesis of porous polymer networks ('polymer imprinting') inside organic templates, ranging from small functional molecules like surfactants over organized particle or micelle packings to microemulsions, have been reviewed by Antonietti and co-workers [72,73].

\subsection{Surfactant vesicle templates}

Mixing cationic and anionic surfactants in aqueous solution can lead to thermodynamically stable spherical bilayer vesicles with submicron diameters and shell thicknesses that are adjustable by the choice of surfactants, their relative concentrations, and properties of the solution such as $\mathrm{pH}$ or salt content. While such spherical surfactant vesicles could and have been used for the polymerization of hollow polymer spheres by incorporating a polymerizable group into the surfactant itself, Kaler and co-workers [138] succeeded to devise a templating process involving standard monomers such as styrene (with divinyl benzene as crosslinker), swelling the organic bilayer of vesicles formed by standard surfactants, with subsequent polymerization to form hollow polymer spheres. The surfactant combinations used for forming the vesicles were cetyltrimethylammonium tosylate (CTAT) with sodium dodecylbenzenesulfonate (SDBS), and cetyltrimethylammonium bromide (CTAB) with sodium octyl sulfate (SOS), respectively. The advantage of this process is, of course, the ready availability of the employed standard components, compared to the costly synthesis of special monomer surfactants. The polymerized hollow spheres were characterized by various techniques, with an average diameter of $60 \mathrm{~nm}$ and a shell thickness of less than $10 \mathrm{~nm}$. The hollow spheres were found to be quite robust against treatments like drying and resuspending in water. Various surface modification strategies were discussed in order to stabilize the aqueous suspensions of these hollow polystyrene spheres [138].

\subsection{Templating based on microemulsions, emulsions and latex particle suspensions}

Emulsions and microemulsions are usually ternary systems formed by oil, water, and surfactants. In microemulsions, the segregation takes place on a shorter length scale. They are thermodynamically stable. Emulsions and microemulsions usually have well-defined interfaces that can be applied as synthetic templates. A typical work was reported by a collaboration of Ying and Stucky [51]. They used microemulsions formed by water, Pluronic P123 $\left(\mathrm{E}_{20} \mathrm{P}_{70} \mathrm{E}_{20}\right)$ and 1,3,5-trimethylbenzene (TMB) to fabricate siliceous mesostructured cellular foams (MCFs) with well-defined ultralarge mesopores and hydrothermally robust frameworks. The MCFs consisted of uniform spherical cells of diameters in the 24-42 nm range and showed large BET (Brunauer-
Emmet-Teller) surface area porosities. Narrowly size distributed windows with tunable size connected the cells. The authors pointed out that the MCFs should have unique advantages as catalyst supports and separation media for processes involving large molecules. The high porosities also make MCFs promising for electrical and insulation applications.

A large number of biologically and industrially important emulsions and dispersions are made from polymers and surfactants. The interplay between the polymers and the surfactants can affect the interface formation and the resultant nano- and microstructures of the dispersion [139]. Meier and co-workers [135-137, 140-145] have made a series of studies on this topic, using a variety of polymers, block co-polymers, and surfactants including poly(oxyethylene) and oligooxyethylene alkyl ether surfactants. It is especially interesting that they introduced microemulsion polymerization processes into the procedures by triggering polymerization in certain well-confined regions (e.g. dissolving monomers in the hydrophobic regions). The final products were 'soft' polymer hollow nanospheres formed by chemically connected block co-polymer chains.

Velev et al. [49,50] reported the use of large emulsion droplets as templates to assemble latex particles either on the surface or inside the droplets. Different pathways of this 'emulsion template' technique were devised, as shown in Fig. 9, depending on which various types of microstructured hollow or solid spherical particles could be synthesized. The crucial part of this process was to tune the surface charges and properties of the latex particles in order to drive them to the correct location in the emulsion domain structure.

Xia and co-workers [146] used a different approach that involved latex particles as templates to form hollow spheres of inorganic compounds, such as $\mathrm{TiO}_{2}$ and $\mathrm{SnO}_{2}$. The highly uniform latex particles provided an ideal matrix for structure control. The final products usually have larger sizes up to submicrons and thick walls. Electron microscope studies revealed that the final products, thick-wall $\mathrm{TiO}_{2}$ beads, were relatively monodisperse in size. Such techniques are also applicable to produce nanoporous metals, e.g. nanoporous gold with pore sizes between $300 \mathrm{~nm}$ and $1 \mu \mathrm{m}$ and a high degree of long-range order [147]. Recently, Caruso [148] reported the applicability of the layer-by-layer (LbL) technique combined with the templating technique for the formation of a range of polymer-core inorganic-shell particles.

A couple of individual reviews have appeared to summarize these new developments $[149,150]$. The basis of this method is the electrostatic association between alternatively deposited, oppositely charged species. An extension of this approach is to remove the latex cores and to form hollow spherical particles. There are several different methods to produce hollow spheres, such as nozzle-reactor 


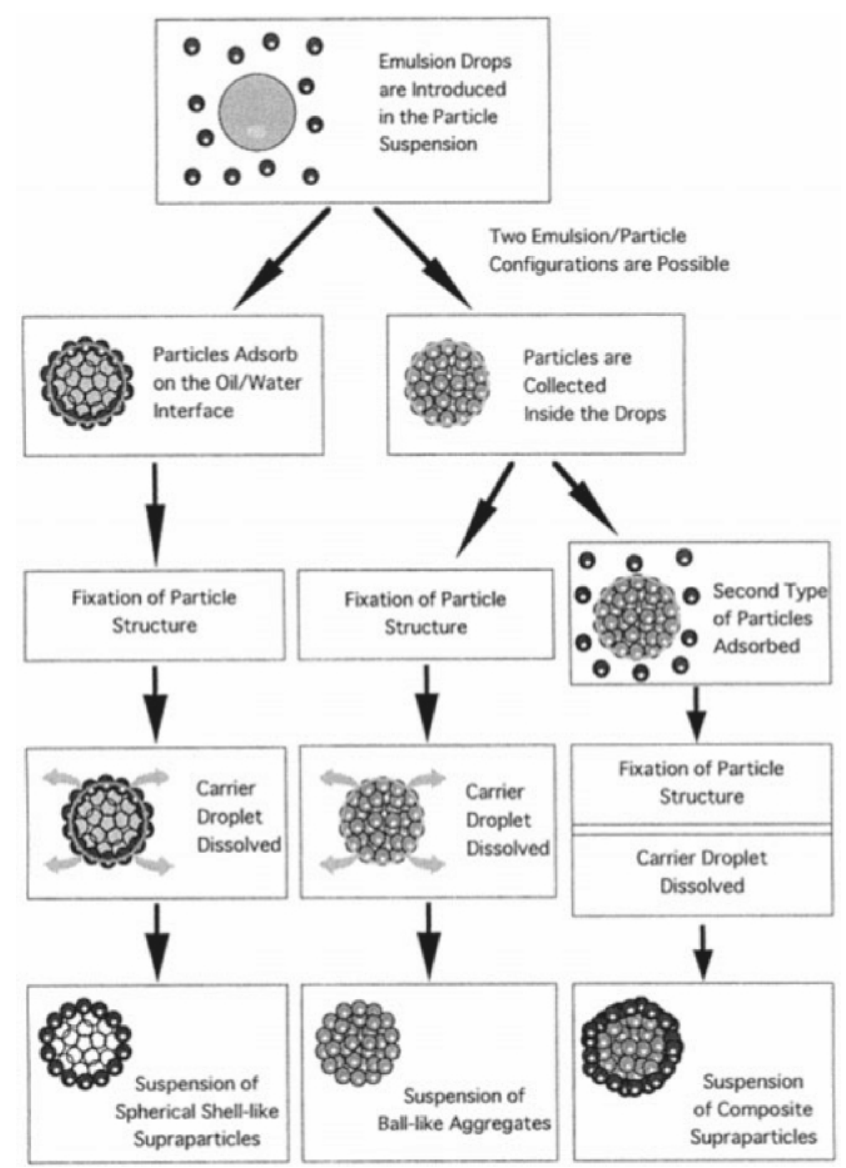

Fig. 9. Different pathways of the emulsion template technique to produce microstructured hollow spheres (Reproduced with permission from Langmuir 1996;12(10):2374. (C) 1996 American Chemical Society [49]).

systems, sacrificial core, and emulsion/water extraction techniques. Large hollow ceramic spheres in $\mathrm{mm}$ size are usually prepared by using nozzle-reactor techniques, resulting in very thick walls (between 40 and $200 \mu \mathrm{m}$ ).

\subsection{Sol-gel templating techniques}

A widely adopted route to synthesize inorganic nanomaterials is to first add inorganic reagent(s) into the system with templates, where the reagent(s) selectively reside in one phase, depending on its (their) solubility or charge interactions. The existence of these reagents, e.g. inorganic salts, should not alter the structure of the templates or induce any phase transition, although slight changes in the dimension sometimes cannot be avoided.

There are several ways to trigger the inorganic reactions. A widely employed process is to combine 'sol-gel chemistry' with nanofabrication, as reported by Martin and co-workers [151,152]. They started with a solution containing reagents and structure-directing materials (block co-polymers or surfactants). After the reaction, the product formed a solid phase mixed with self-organized template.
The template could then be removed by calcination at high temperatures, so that only the porous inorganic product with regularly packed holes remained. This and similar processes have been successfully used to synthesize mesoporous silica and other simple metal oxides, as represented by large amounts of work done by the Stucky group and the Martin group. A very simple and general route to synthesize many transition metal oxide nanomaterials has been presented by Yang et al. [67]. The preparation of CdS hollow nanotubules discussed in Section 4.1 from a hexagonal surfactant gel report by Stupp and co-workers [91] also belongs to this class.

Antonietti and co-workers [153] used 'sol-gel nanocasting' to imprint the lyotropic template structure of non-ionic surfactants onto mesoporous silica. The resulting silica was investigated by SAXS, TEM and gas adsorption (BET) techniques, revealing different hierarchies of pore size ranges and their dependencies on the organic template.

\subsection{Membrane-based nanofabrication}

Another important templating approach is the use of 
nanoporous membranes with cylindrical holes $[6,151,152$, 154-161]. Among the widely reported hosts, commercial particle track-etched membranes (PTMs) and alumina membranes are the two that have drawn the most attention. This technique allows chemical or electrochemical synthesis of thin wires or hollow tubules in the cylindrical pores of the template membrane. Applicable materials include not only metals but also polymers to be formed in these confined geometries. Many applications focus on materials with interesting electric or magnetic properties. More involved morphologies like concentric multilayers are also possible. Depending on the desired application, the created nanocylinders can be extracted from the polymer membrane or they can be left inside to form composite materials with interesting properties.

Several factors, such as pore size, pore density and pore shape, are important to determine the morphology of the final product. Widely used PTMs are made by bombarding a polymer film by high-energy heavy ions accelerated in a cyclotron. Then, the film is etched in an adequate medium where tracks are revealed, leading to the formation of pores whose diameter depends on the etching time. Recently, more reliable and reproducible nanoporous PTMs have been prepared with a mean pore size between 100 and $150 \mathrm{~nm}$, a narrow pore size distribution, and perfect cylindrical pores with smooth walls and parallel arrangements of the pores across the membrane [152].

Martin and co-workers [6] reported different chemical strategies to prepare different typical tubule structures, including electroless deposition of $\mathrm{Au}$, electropolymerization of conductive and insulating polymers, electrodeposition of metals and semiconductors, carbonization of polymer precursors, chemical vapor deposition synthesis and sol-gel synthesis. Combining different approaches can lead to concentric-tubular micro- and nanocomposites, i.e. tubular structures consisting of an outer tubule of one material surrounding inner tubules of different materials. Some examples of these composites were Au/polyphenylene oxide/polypyrrole, carbon/polyacrylonitrile/Au, $\mathrm{TiS}_{2} / \mathrm{Au}$, $\mathrm{TiO}_{2} / \mathrm{Au}$, and $\mathrm{ZnO} / \mathrm{Au}$. The authors expected that these composites might find applications in microelectronics, chemical sensors and electrochemical energy production.

\subsection{Nanofabrication inside dendrimer networks}

Dendrimers are a kind of monodisperse, hyperbranched polymer, possessing a very high concentration of surface functional groups. There are usually many terminal groups covalently bonded to the body of the dendrimers, and the hydrophobicity of the terminal groups determines the solubility of the dendrimers in different solvents, i.e. dendrimers with hydrophobic terminal groups are able to be dissolved in non-polar solvents, but not in polar solvents, and vice versa. For the same kind of dendrimer, different synthetic approaches can lead to the formation of different generations of final products, with the higher generation of dendrimers having much higher molecular weight and overall size, as well as larger cage spaces among branches. By controlling the synthetic conditions, chemists now are able to make dendrimers with desired generations. These uniform polymeric clusters offer novel opportunities for nanofabrication.

Crooks and co-workers $[13,52,54]$ used amine-terminated polyamidoamine (PAMAM) dendrimers as containing molecules to produce $\mathrm{Cu}$ metal nanoparticles. The $\mathrm{Cu}^{2+}$ ions were bonded to the dendrimers at a certain $\mathrm{pH}$, and were reduced by $\mathrm{NaBH}_{4}$. The $\mathrm{Cu}$ clusters grew and were stabilized inside the dendrimers. The intradendrimer $\mathrm{Cu}$ clusters were very small in size (1.8 $\mathrm{nm}$ diameter) and could remain stable for over a week in an oxygen-free solution, but would be reverted to intradendrimer $\mathrm{Cu}^{2+}$ ions in airsaturated solutions. At very high $\mathrm{Cu}^{2+}$ concentrations, both inter- and intradendrimer $\mathrm{Cu}$ clusters could be observed, with the former one having much larger size $(9 \pm 4 \mathrm{~nm})$ and polydispersity. By choosing dendrimers of different generations, nanoparticles with different sizes can be synthesized. A similar approach was also reported independently by Balogh and Tomalia [53] at about the same time. The application of dendrimers to grow different metal nanoparticles was further developed by contributions from Esumi et al. [162], Amis and co-workers [58], and others [163-165]. This technique is suitable to fabricate nanoparticles with well-defined sizes, although in many cases a relatively broad size distribution is unavoidable.

In a different approach, Larsen et al. used the generation 4.0 PAMAM dendrimers as templates for preparing amorphous silica $[55,57]$. Here, the quasi-spherical dendrimers acted similar to micelles reported earlier, where the nanostructures were calcinated and removed after the formation of the silica, so that the porous materials with ordered, nanoscaled spherical holes would be obtained.

The highly uniform nature of the nanocompartments in dendrimers makes them suitable templates for the nanofabrication of highly monodisperse metal nanoparticles which is important in order to exploit their unique electrical and non-linear optical properties.

\subsection{Electric field-induced nanopatterns in polymer films}

Recently, Russell and co-workers [166,167] reported a novel method to create nanostructures where the nanoscopic order could be induced and/or controlled physically by imposing an external field. A thin polymer film (e.g. polystyrene) was deposited on one of two electrodes separated by a short distance of $<1 \mu \mathrm{m}$. The electrostatic pressure added at the polymer/air interface caused an instability with a well-defined wavelength inside the polymer film. Gradually, the polymer columns spanned the gap between the two electrodes. If the top electrode had a topographical structure, the instability first occurred at the locations where the distance between the electrodes was smallest which subsequently replicated the electrode 


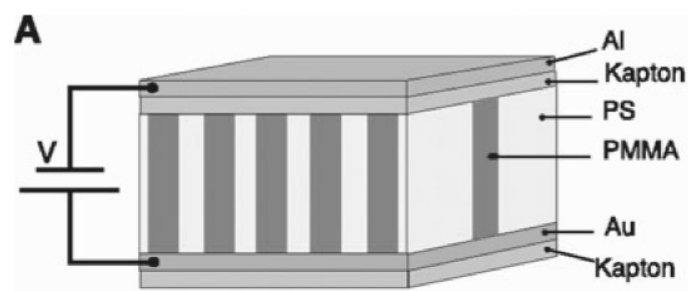

B

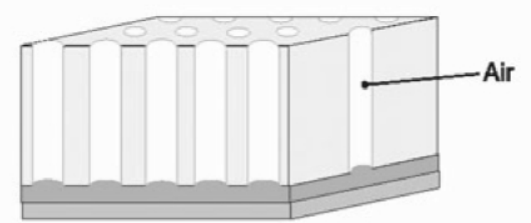

C

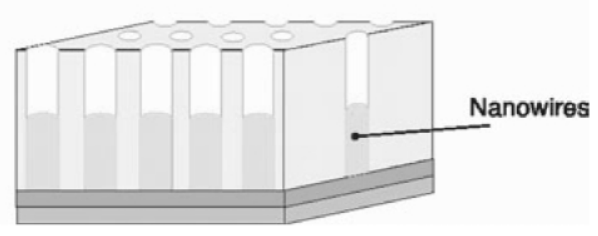

Fig. 10. (A) Two-dimensional hexagonal PS-PMMA diblock co-polymer aligned in an electrical field; (B) minority component removed; (C) electrodeposited nanowires (Reproduced with permission from Science 2000;290(5499):2126. (C) 2000 American Association for the Advancement of Science [167]).

pattern. By using this idea, Russell and co-workers generated a simple route to fabricate ultrahigh-density arrays of nanowires with high aspect ratios.

Asymmetric block co-polymers of polystyrene- $b$-polymethylmethacrylate (PS-PMMA) were used to form electrically induced templates (hexagonal arrays) between the electrodes, as shown in Fig. 10, while the dimensions and lateral density of the array could be determined by segmental interactions and the co-polymer molecular weight. The PMMA blocks formed isolated cylindrical rods under electrostatic pressure, which could be removed after the formation of the ordered arrays of nanowires so that a nanoporous film was formed. Finally, by electrodeposition, nanowires could be grown in the porous template, forming an ordered array of nanowires in a polymer matrix. The authors successfully grew over $1.93 \times 10^{11}$ Co wires (14 nm in diameter) within just $1 \mathrm{~cm}^{2}$. The authors further pointed out that this technique might find many promising applications in broader areas, such as nanoreactors, templates to transfer the structure of block co-polymers, as well as controlling the lateral placement of nanostructures on a surface. The unique advantage of this technique is that it can create highly ordered patterns on surfaces, with the pattern size on a nanometer scale, much smaller than that from soft lithography. Until recently, most of their work has been concentrated on PMMS cylinders with PS matrices, i.e. creating hollow nanotubes within a PS matrix.

\subsection{Nanoreactions induced by $\gamma$-irradiation}

Another route was reported by Xie et al. [168-170] which was referred to as 'simultaneous in situ formation' (SISF) technique by using intense $\gamma$-irradiation to trigger the inorganic reactions. Several kinds of inorganic nanowires were prepared in the presence of liquid crystal template by using this method. A typical reaction mechanism $(\mathrm{ZnS})$ is described below:

$$
\begin{aligned}
& \mathrm{H}_{2} \mathrm{O} \stackrel{\text { irradiation }}{\longrightarrow} \mathrm{e}_{\mathrm{aq}}^{-}, \mathrm{H}_{3} \mathrm{O}^{+}, \mathrm{H}^{\cdot}, \mathrm{H}_{2}, \mathrm{OH}, \mathrm{H}_{2} \mathrm{O}_{2} \\
& \mathrm{Zn}^{2+}+\mathrm{e}_{\mathrm{aq}}^{-} \longrightarrow \mathrm{Zn}^{+} \\
& \mathrm{CS}_{2} \stackrel{\text { irradiation }}{\longrightarrow} \mathrm{S}^{\cdot}+\mathrm{CS} \\
& \left(\mathrm{NH}_{2}\right)_{2} \mathrm{CS}+2 \mathrm{OH}^{\cdot} \stackrel{\text { irradiation }}{\longrightarrow} \mathrm{S}^{\cdot}+2 \mathrm{NH}_{3}+\mathrm{CO}_{2} \\
& \mathrm{Zn}^{+}+\mathrm{S}^{\cdot}+\mathrm{e}_{\mathrm{aq}}^{-} \longrightarrow \mathrm{ZnS}
\end{aligned}
$$

The $\gamma$-irradiation generated radicals that would simultaneously partially reduce $\mathrm{Zn}^{2+}$ to $\mathrm{Zn}^{+}$. The latter would further react with another free radical $\mathrm{S}^{*}$ to the final product. This approach avoided the use of $\mathrm{H}_{2} \mathrm{~S}$ gas. The long $\mathrm{ZnS}$ nanowires (0.6-1.2 $\mu \mathrm{m}$ in length, $5 \mathrm{~nm}$ diameter) were able to keep their structures after removing the templates. Furthermore, it was observed that the nanowires could again pack into bundles with ordered hexagonal packings.

\subsection{Biomimetic synthesis of inorganic nanomaterials and nanocomposites}

Biomimetic synthesis deals with the formation of inorganic crystals embedded in organic matrices, thereby trying to understand and reproduce the corresponding processes taking place in biological systems, e.g. the mineralization of collagen leading to bone. After formation of the inorganic nanocrystals, the organic matrix is usually not removed so that the final product is a composite material, often characterized by unique mechanical properties such as a very high toughness [3]. However, it should be recognized that our present synthetic capabilities are far from nature's ability to completely alter and improve the mechanical properties of carbonates and phosphates with smallest amounts of embedded organic material.

Antonietti et al. [68] reported the use of a triblock co-polymer PEO-PMAA- $\mathrm{C}_{12}$ (with PMAA denoting polymethacrylic acid and $\mathrm{C}_{12}$ a dodecyl chain) to form inorganic nanoparticles such as $\mathrm{CaCO}_{3}$. Among the three blocks in the polymer, two blocks are hydrophilic (long chain PEO and short chain PMAA). The polymer chains would form micelles in aqueous solution with PEO and PMAA being micellar shells. The idea was to use the charged PMAA block to interact with inorganic salts and surfaces, and to use PEO to increase the solubility of the system in water. At different acidic $\mathrm{pH}$ conditions, two new types of discrete nested structures, consisting of hybrid nanofilaments arranged to give an unusual neuron-like 

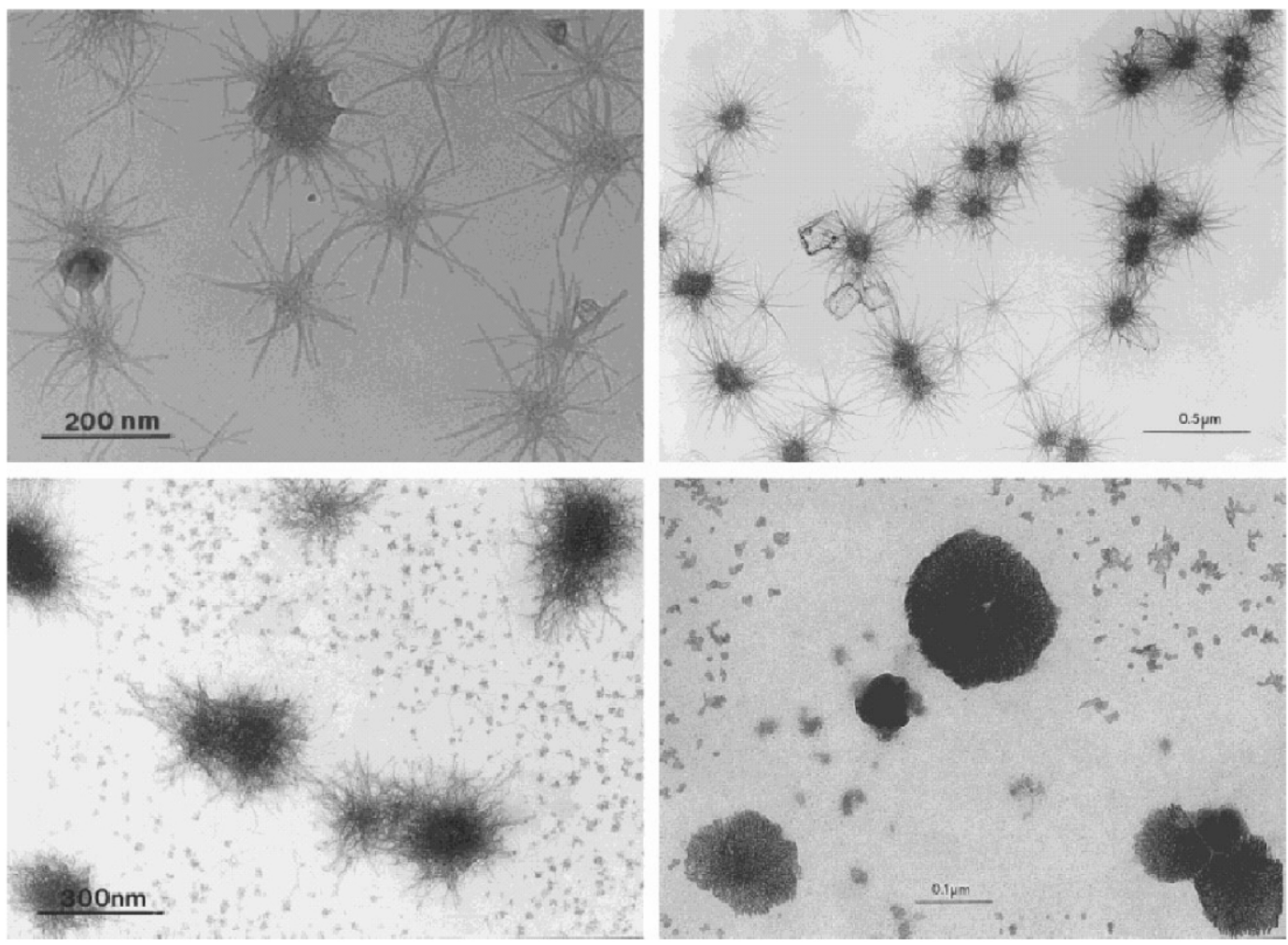

Fig. 11. Transmission electromicrographs showing the growth of neuron-like calcium phosphate/polymer mesostructures at $\mathrm{pH} 4.5$ and 5.0 (Reproduced with permission from Chem-Eur J 1998;4(12):2493. (C) 1998 Wiley-VCH [68]).

morphology were synthesized, see Fig. 11. The co-operative interactions at a local level between $\mathrm{Ca}_{3}\left(\mathrm{PO}_{4}\right)_{2}$ clusters and the polymer units could be responsible for the highly anisotropic nature of the product. After aging, a second hybrid morphology consisting of compact aggregates appeared, which showed the interlocked layer structure of an ordered inorganic/organic mesophase with a domain size of $3 \mathrm{~nm}$. The authors proposed that the new materials might be useful as novel ceramics precursors, reinforcing filters or biomedical implants.

While the various chemical modifications of calcium carbonates [69] and phosphates have the highest biological abundance and have therefore been extensively studied in biomimetic approaches, biomimetic synthesis is not limited to those inorganic compounds only. For example, in a collaboration of Antonietti's and Mann's group [171], nanofibers of $\mathrm{BaSO}_{4}$ with non-trivial morphologies have been synthesized using a polymer templating process.

\subsection{Non-template nanofabrication in polymer solution}

Not all nanofabrication processes involving polymers or surfactants take place in form of templating processes in the sense that the final nanostructured product is more or less a replica of the original nanostructured polymer or surfactant matrix. In these cases, kinetic aspects of the system need to be considered, diffusion and transport properties of the involved components and their dependence on hydrophilic and/or electrostatic interactions, nucleation and growth or spinodal decomposition concepts in the formation of the resulting products, and so on. For the preparation of organic nanoparticles in aqueous solution, with physiological or technological applications in mind, this field has been reviewed in detail by Horn and Rieger [172].

An example for a non-template polymer solution-based synthesis of a highly ordered nanostructured inorganic material was provided by our research group. Large spherical polyoxomolybdate clusters were synthesized in aqueous solution in the presence of a commercial triblock co-polymer, $\mathrm{E}_{45} \mathrm{~B}_{14} \mathrm{E}_{45}$ or homogeneous long chain PEO (polyoxyethylene) [173]. The spheres which contained a mixture of oxidation states $\mathrm{Mo}(\mathrm{V})$ and $\mathrm{Mo}(\mathrm{VI})$ were synthesized by the decomposition of the soluble precursor compound $\mathrm{MoO}_{2}(\mathrm{OH})(\mathrm{OOH})$. After the reaction and removal of the co-polymer chains as well as water, a unique crystal with basic units made up of uniform hollow polyoxomolybdate nanospheres was synthesized. It is particularly noteworthy that SAXS/WAXD images, as shown in Fig. 12, revealed over 100 orders of scattering peaks that could be indexed following a cubic symmetry. The 7th, 15th, 23rd, 28th, and 31st order scattering peaks were absent, indicating that these nanospheres were packed 


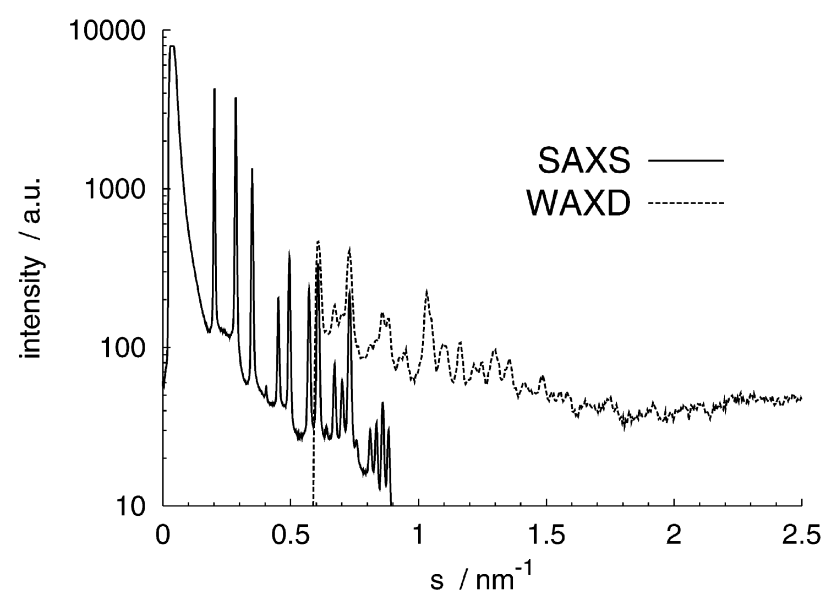

Fig. 12. SAXS/WAXD patterns of a polyoxomolybdate structure synthesized by a non-templating process. The SAXS pattern shows a series of sharp peaks, which are indexable following a cubic symmetry with a lattice constant of $5.0 \mathrm{~nm}$. The WAXD pattern extends this peak series to larger angles up to more than 100 orders. The observed degree of long-range order is highly unusual for a structure with such a large unit cell.

into a rare primitive cubic $(\mathrm{pc})$ structure. The material had a similar scattering curve and, presumably, structure as that of the Linde type-A zeolite, but with a much larger unit cell size $(5 \mathrm{~nm}$ versus $<1 \mathrm{~nm})$.

The TEM micrograph, as shown in Fig. 13, clearly revealed the crystal formation packed of 5-nm diameter spheres which, according to density estimations, must be hollow. Total crystallite sizes were small, approaching the micrometer scale. Fig. 14 shows a crude visualization of

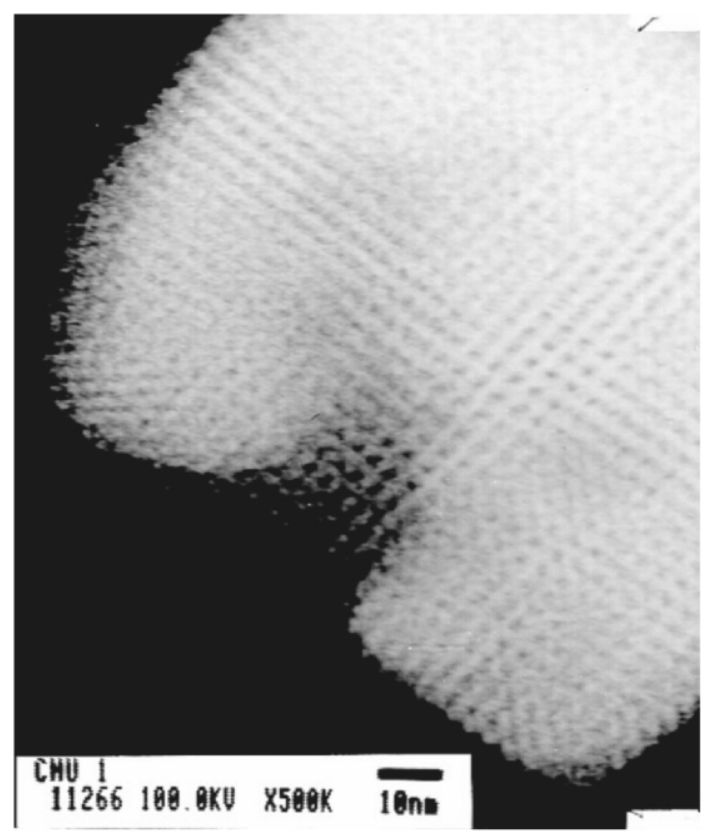

Fig. 13. Transmission electromicrographs of a polyoxomolybdate structure, apparently showing the 100 face of a primitive cubic crystal with a lattice constant of $5.0 \mathrm{~nm}$. this structure that is compatible with the scattering data in Fig. 12 and the TEM picture in Fig. 13. Whether or not there are connections between the hollow interiors of these spherical units or whether there are systematic holes in the spherical shells cannot be decided based on our existing data.

Inorganic chemists synthesized a smaller hollow polyoxomolybdate cluster with a diameter of $2.5 \mathrm{~nm}$, which had a well-defined fullerene-like spherical structure containing exactly 12 pentagons $\left(\mathrm{Mo}\left(\mathrm{Mo}_{5}\right)\right.$ pentagonal bipyramides) with a total of $132 \mathrm{Mo}\left(60 \mathrm{Mo}^{\mathrm{V}}\right.$ and $\left.72 \mathrm{Mo}^{\mathrm{VI}}\right)$ atoms [174]. The larger polyoxomolybdate spheres synthesized in the presence of the polymer network represented a different

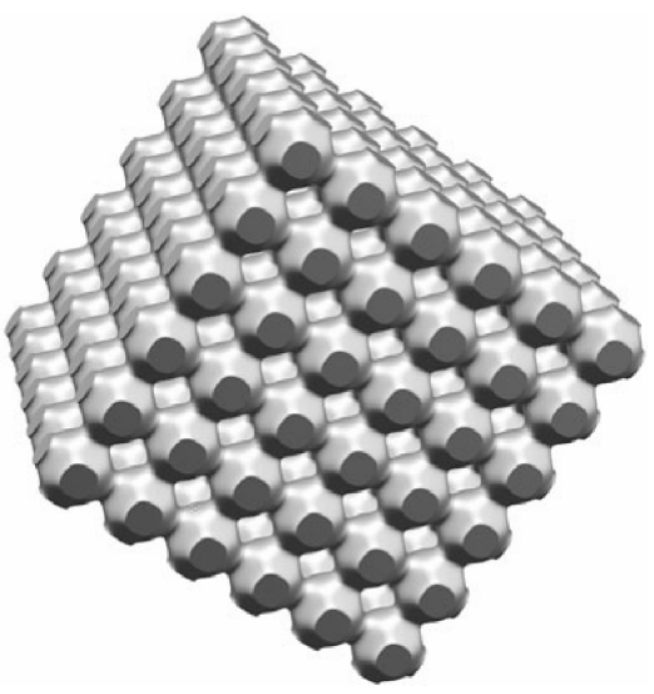

Fig. 14. Structure model for the primitive cubic packing of presumably hollow spherical structural units, compatible with the scattering data in Fig. 12 and the TEM picture in Fig. 13. 
kind of shell structure, possibly some higher homologue of the fullerene structure ('super-fullerene') in which case the expected approach of a non-spherical shape with flat polyhedron-like faces could explain the unusual primitive cubic packing.

The functional role of the block co-polymer was quite complicated in the whole process. It certainly did not act as a template since the same results could also be obtained using disordered PEO-containing polymer solutions. On the contrary, we believe that the PEO-polymer chains got involved into the reaction by acting as a very weak reducing agent (by using their $-\mathrm{OH}$ end groups) to delicately reduce only a slight amount $(\sim 12 \%)$ of $\mathrm{Mo}(\mathrm{VI})$ to $\mathrm{Mo}(\mathrm{V})$. At the same time, the viscous, entangled polymer network offered a unique support to stabilize the final product to grow into larger clusters. It took about $6-8$ weeks to complete the inorganic reaction, much slower than usual inorganic reactions. Furthermore, the final product cannot be synthesized with short-chain, $-\mathrm{OH}$ containing reducing agents (e.g. glycerol). This new approach may open opportunities to prepare other large molecules with ordered structures and containing mixed-valence metal ions.

\section{Conclusions and outlook}

Polymers in solutions have been widely applied as templates to fabricate nanostructured materials. The selfassembled amphiphilic block co-polymers (and surfactants), the nanoporous polymer membranes, dendrimers, emulsions and microemulsions, latex particles, as well as ion-containing polymers have been employed in different processes due to their specific features. The variety in structures and the dimensions of templates provided by different polymer systems enabled scientists to create novel nanomorphologies, such as spheres, solid rods, hollow wires and cylinders, fabrils, as well as multilayered tubules. Besides simply providing synthetic templates or unique synthetic compartments, the functions of polymers have further been extended to more complicated approaches, such as taking part in the reactions, or acting as non-template, reactioncontrolled agents. The nanostructures prepared in the presence of polymer systems have nearly covered all the major materials, such as metals, inorganic compounds, polymers, and inorganic/polymer composites. This dynamic field shall grow vigorously in the near future and create new materials with interesting morphologies for different applications, for example, in photonics, electronics, catalysis, and microsensors.

\section{Acknowledgements}

BC gratefully acknowledges support of this work by the National Science Foundation (DMR9984102) and the US
Department of Energy (DEFG0286ER45237.016 and DEFG0299ER45760). TL acknowledges support by the US Department of Energy, Division of Materials Science, under Contract No. DE-AC02-98CH10886. CB gratefully acknowledges support of the Alexander von Humboldt Foundation as a Feodor Lynen Fellow.

\section{References}

[1] Muthukumar M, Ober CK, Thomas EL. Science 1997; 277(5330):1225-32.

[2] Yang PD, Deng T, Zhao DY, Feng PY, Pine D, Chmelka BF, Whitesides GM, Stucky GD. Science 1998;282(5397): 2244-6.

[3] Mann S. Nature 1993;365(6446):499-505.

[4] Bein T, Stucky GD. Chem Mater 1996;8(8):1569-70.

[5] Ying JY, Mehnert CP, Wong MS. Angew Chem, Int Ed 1999; 38(1/2):56-77.

[6] Martin CR. Chem Mater 1996;8(8):1739-46.

[7] Huo QS, Margolese DI, Ciesla U, Demuth DG, Feng PY, Gier TE, Sieger P, Firouzi A, Chmelka BF, Schuth F, Stucky GD. Chem Mater 1994;6(8):1176-91.

[8] Zhao DY, Yang PD, Huo QS, Chmelka BF, Stucky GD. Curr Opin Solid State Mater Sci 1998;3(1):111-21.

[9] Xia YN, Whitesides GM. Annu Rev Mater Sci 1998;28: 153-84.

[10] Xia YN, Whitesides GM. Angew Chem, Int Ed 1998;37(5): 551-75.

[11] Whitesides GM, Stroock AD. Phys Today 2001;54(6):42-8.

[12] Harnett CK, Satyalakshmi KM, Craighead HG. Langmuir 2001;17(1):178-82.

[13] Ghosh P, Lackowski WM, Crooks RM. Macromolecules 2001;34(5):1230-6.

[14] Quake SR, Scherer A. Science 2000;290(5496):1536-40.

[15] Tuzar Z, Kratochvil P. Micelles of block and graft copolymers in solution. In: Matijevic E, editor. Surface and colloid science, vol. 15. New York: Plenum Press; 1993.

[16] Kon-no K. Properties and applications of reversed micelles. In: Matijevic E, editor. Surface and colloid science, vol. 15. New York: Plenum Press; 1993.

[17] Chu B, Zhou Z. Physical chemistry of polyoxyalkylene block copolymer surfactants. In: Nace VM, editor. Nonionic surfactants. New York: Marcel Dekker; 1996.

[18] Liu T, Zhou ZK, Wu CH, Chu B, Schneider DK, Nace VM. J Phys Chem B 1997;101(43):8808-15.

[19] Liu T, Liu L-Z, Chu B. Formation of amphiphilic block copolymer micelles in nonaqueous solvents. In: Alexandridis P, Lindman B, editors. Block copolymers: self-assembly and applications. Amsterdam: Elsevier; 2000.

[20] Liu T, Nace VM, Chu B. J Phys Chem B 1997;101(41): 8074-8.

[21] Utiyama H, Takenaka K, Mizumori M, Fukuda M, Tsunashi Y, Kurata M. Macromolecules 1974;7(4):515-20.

[22] Antonietti M, Heinz S, Schmidt M, Rosenauer C. Macromolecules 1994;27(12):3276-81.

[23] Castelletto V, Itri R, Amaral LQ. J Chem Phys 1997;107(2): 638-44.

[24] Leaver M, Rajagopalan V, Ulf O, Mortensen K. Phys Chem Chem Phys 2000;2(13):2951-8. 
[25] Wu GW, Zhou ZK, Chu B. J Polym Sci, Part B: Polym Phys 1993;31(13):2035-47.

[26] Mortensen K, Brown W, Jorgensen E. Macromolecules 1994; 27(20):5654-66.

[27] Wanka G, Hoffmann H, Ulbricht W. Colloid Polym Sci 1990; 268(2):101-17.

[28] Mortensen K, Brown W, Norden B. Phys Rev Lett 1992; 68(15):2340-3.

[29] Alexandridis P, Andersson K. J Phys Chem B 1997;101(41): 8103-11.

[30] Holmqvist P, Alexandridis P, Lindman B. Macromolecules 1997;30(22):6788-97.

[31] Alexandridis P, Olsson U, Lindman B. Langmuir 1996;12(6): 1419-22.

[32] Alexandridis P, Olsson U, Lindman B. Langmuir 1998; 14(10):2627-38.

[33] Mao GP, Wang JG, Clingman SR, Ober CK, Chen JT, Thomas EL. Macromolecules 1997;30(9):2556-67.

[34] Thomas EL, Chen JT, Orourke MJE, Ober CK, Mao GP. Macromol Symp 1997;117:241-56.

[35] Ober CK, Wang JG, Mao GP, Kramer EJ, Chen JT, Thomas EL. Macromol Symp 1997;117:141-52.

[36] Avgeropoulos A, Dair BJ, Hadjichristidis N, Thomas EL. Macromolecules 1997;30(19):5634-42.

[37] Ruokolainen J, Tanner J, Ikkala O, Brinke G, Thomas EL. Macromolecules 1998;31(11):3532-6.

[38] Sioula S, Hadjichristidis N, Thomas EL. Macromolecules 1998;31(16):5272-7.

[39] Avgeropoulos A, Chan VZH, Lee VY, Ngo D, Miller RD, Hadjichristidis N, Thomas EL. Chem Mater 1998;10(8): 2109-15.

[40] Brinkmann S, Stadler R, Thomas EL. Macromolecules 1998; 31(19):6566-72.

[41] Mattoussi H, Radzilowski LH, Dabbousi BO, Fogg DE, Schrock RR, Thomas EL, Rubner MF, Bawendi MG. J Appl Phys 1999;86(8):4390-9.

[42] Ruokolainen J, Saariaho M, Ikkala O, Brinke G, Thomas EL, Torkkeli M, Serimaa R. Macromolecules 1999;32(4): 1152-8.

[43] Chrissopoulou K, Tselikas Y, Anastasiadis SH, Fytas G, Semenov AN, Fleischer G, Hadjichristidis N, Thomas EL. Macromolecules 1999;32(15):5115-26.

[44] Albalak RJ, Thomas EL, Capel MS. Polymer 1997;38(15): 3819-25.

[45] Albalak RJ, Capel MS, Thomas EL. Polymer 1998;39(8/9): 1647-56.

[46] Dair BJ, Honeker CC, Alward DB, Avgeropoulos A, Hadjichristidis N, Fetters LJ, Capel M, Thomas EL. Macromolecules 1999;32(24):8145-52.

[47] Park C, Simmons S, Fetters LJ, Hsiao B, Yeh F, Thomas EL. Polymer 2000;41(8):2971-7.

[48] Antonietti M, Basten R, Lohmann S. Macromol Chem Phys 1995;196(2):441-66.

[49] Velev OD, Furusawa K, Nagayama K. Langmuir 1996; 12(10):2374-84.

[50] Velev OD, Furusawa K, Nagayama K. Langmuir 1996; 12(10):2385-91.

[51] Schmidt-Winkel P, Lukens WW, Yang PD, Margolese DI, Lettow JS, Ying JY, Stucky GD. Chem Mater 2000;12(3): 686-96.
[52] Zhao MQ, Sun L, Crooks RM. J Am Chem Soc 1998; 120(19):4877-8.

[53] Balogh L, Tomalia DA. J Am Chem Soc 1998;120(29): 7355-6.

[54] Chechik V, Zhao MQ, Crooks RM. J Am Chem Soc 1999; 121(20):4910-1.

[55] Larsen G, Lotero E, Marquez M. J Phys Chem B 2000; 104(20):4840-3.

[56] Nguyen C, Hawker CJ, Miller RD, Huang E, Hedrick JL, Gauderon R, Hilborn JG. Macromolecules 2000;33(11): 4281-4.

[57] Larsen G, Lotero E, Marquez M. Chem Mater 2000;12(6): 1513-5.

[58] Gröhn F, Bauer BJ, Akpalu YA, Jackson CL, Amis EJ. Macromolecules 2000;33(16):6042-50.

[59] Burger C, Zhou S, Chu B. Nanostructures of polyelectrolyte-surfactant complexes and their applications. In: Tripathy SK, Kumar J, Nalwa HS, editors. Handbook of polyelectrolytes and their applications, vol. 3. Stevenson Ranch, California: American Scientific Publishers; 2002. p. 125-41. chapter 7 .

[60] Koga T, Zhou S, Chu B, Fulton JL, Yang S, Ober CK, Erman B. Rev Sci Instrum 2001;72(6):2679-85.

[61] Zhao DY, Feng JL, Huo QS, Melosh N, Fredrickson GH, Chmelka BF, Stucky GD. Science 1998;279(5350):548-52.

[62] Monnier A, Schuth F, Huo Q, Kumar D, Margolese DI, Maxwell RS, Stucky GD, Krishnamurty M, Petroff P, Firouzi A, Janicke M, Chmelka BF. Science 1993;261(5126): 1299-303.

[63] Firouzi A, Kumar D, Bull LM, Besier T, Sieger P, Huo Q, Walker SA, Zasadzinski JA, Glinka C, Nicol J, Margolese DI, Stucky GD, Chmelka BF. Science 1995;267(5201): $1138-43$.

[64] Yang PD, Zhao DY, Margolese DI, Chmelka BF, Stucky GD. Nature 1998;396(6707):152-5.

[65] Zhao DY, Huo QS, Feng JL, Chmelka BF, Stucky GD. J Am Chem Soc 1998;120(24):6024-36.

[66] Zhao DY, Huo QS, Feng JL, Kim JM, Han YJ, Stucky GD. Chem Mater 1999;11(10):2668-72.

[67] Yang PD, Zhao DY, Margolese DI, Chmelka BF, Stucky GD. Chem Mater 1999;11(10):2813-26

[68] Antonietti M, Breulmann M, Göltner CG, Cölfen H, Wong KKW, Walsh D, Mann S. Chem-Eur J 1998;4(12): 2493-500.

[69] Cölfen H, Antonietti M. Langmuir 1998;14(3):582-9.

[70] Sedlak M, Antonietti M, Cölfen H. Macromol Chem Phys 1998;199(2):247-54.

[71] Antonietti M, Caruso RA, Göltner CG, Weissenberger MC. Macromolecules 1999;32(5):1383-9.

[72] Hentze HP, Antonietti M. Curr Opin Solid State Mater Sci 2001;5(4):343-53.

[73] Antonietti M. Curr Opin Colloid Interf Sci 2001;6(3):244-8.

[74] Ogawa M. J Am Chem Soc 1994;116(17):7941-2.

[75] Tanev PT, Pinnavaia TJ. Science 1995;267(5199):865-7.

[76] Rangan KK, Billinge SJL, Petkov V, Heising J, Kanatzidis MG. Chem Mater 1999;11(10):2629-32.

[77] Ulrich R, Du Chesne A, Templin M, Wiesner U. Adv Mater 1999;11(2):141-6.

[78] Iijima M, Nagasaki Y, Okada T, Kato M, Kataoka K. Macromolecules 1999;32(4):1140-6. 
[79] Kresge CT, Leonowicz ME, Roth WJ, Vartuli JC, Beck JS. Nature 1992;359(6397):710-2.

[80] Beck JS, Vartuli JC, Roth WJ, Leonowicz ME, Kresge CT, Schmitt KD, Chu CTW, Olson DH, Sheppard EW, McCullen SB, Higgins JB, Schlenker JL. J Am Chem Soc 1992; 114(27): 10834-43.

[81] Brinker CJ. Curr Opin Solid State Mater Sci 1996;1(6): 798-805.

[82] Vartuli JC, Kresge CT, Roth WJ, McCullen SB, Beck JS, Schmitt KD, Leonowicz ME, Lutner JD, Sheppard EW. Designed synthesis of mesoporous molecular sieve systems using surfactant-directing agents. In: Moser WR, editor. Advanced catalysts and nanostructured materials: modern synthesis methods. New York: Academic Press; 1996. p. $1-19$.

[83] Stucky GD, Huo QS, Firouzi A, Chmelka BF, Schacht S, Voigtmartin IG, Schuth F. Directed synthesis of organic/ inorganic composite structures. In: Chong H, Ihm SK, Uh YS, editors. Progress in zeolite and microporous materials, studies in surface science and catalysis, vol. 105. Amsterdam: Elsevier; 1997. p. 3-28.

[84] Raman NK, Anderson MT, Brinker CJ. Chem Mater 1996; $8(8): 1682-701$

[85] Antonelli DM, Ying JY. Curr Opin Colloid Interf Sci 1996; 1(4):523-9.

[86] Behrens P. Angew Chem, Int Ed Engl 1996;35(5):515-8.

[87] Zhao XS, Lu GQM, Millar GJ. Ind Engng Chem Res 1996; 35(7):2075-90.

[88] Sayari A. Chem Mater 1996;8(8):1840-52.

[89] Han YJ, Kim JM, Stucky GD. Chem Mater 2000;12(8): 2068-9.

[90] Liu Z, Sakamoto Y, Ohsuna T, Hiraga K, Terasaki O, Ko CH, Shin HJ, Ryoo R. Angew Chem, Int Ed 2000;39(17): 3107-10.

[91] Braun PV, Osenar P, Stupp SI. Nature 1996;380(6572): $325-8$.

[92] Hue QS, Margolese DI, Ciesla U, Feng PY, Gier TE, Sieger P, Leon R, Petroff PM, Schuth F, Stucky GD. Nature 1994; 368(6469):317-21.

[93] Walsh D, Hopwood JD, Mann S. Science 1994;264(5165): $1576-8$.

[94] Kobayashi S, Hanabusa K, Hamasaki N, Kimura M, Shirai H, Shinkai S. Chem Mater 2000;12(6):1523.

[95] Filankembo A, Pileni MP. J Phys Chem B 2000;104(25): 5865-8.

[96] Tanori J, Pileni MP. Adv Mater 1995;7(10):862.

[97] Xu RL, Winnik MA, Riess G, Chu B, Croucher MD. Macromolecules 1992;25(2):644-52.

[98] d'Oliveira JMR, Xu RL, Jensma T, Winnik MA, Hruska Z, Hurtrez G, Riess G, Martinho JMG, Croucher MD. Langmuir 1993;9(4):1092-7.

[99] Xu RL, Dunger G, Winnik MA, Martinho JMG, d'Oliveira JMR. Langmuir 1994;10(9):2977-84.

[100] Guo A, Liu GJ, Tao J. Macromolecules 1996;29(7):2487-93.

[101] Farinha JPS, d'Oliveira JMR, Martinho JMG, Xu RL, Winnik MA. Langmuir 1998;14(9):2291-6.

[102] Henselwood F, Liu GJ. Macromolecules 1997;30(3): 488-93.

[103] Henselwood F, Liu GJ. Macromolecules 1998;31(13): 4213-7.

[104] Ding JF, Liu GJ. Chem Mater 1998;10(2):537-42.
[105] Ding JF, Liu GJ. Macromolecules 1998;31(19):6554-8. [106] Ding JF, Liu GJ. J Phys Chem B 1998;102(31):6107-13.

[107] Liu GJ, Ding JF. Chem Engng Technol 1998;21(2):211-3.

[108] Wang GC, Henselwood F, Liu GJ. Langmuir 1998;14(7): 1554-9.

[109] Henselwood F, Wang GC, Liu GJ. J Appl Polym Sci 1998; 70(2):397-408.

[110] Stewart S, Liu GJ. Chem Mater 1999;11(4):1048-54.

[111] Liu GJ, Ding JF, Qiao LJ, Guo A, Dymov BP, Gleeson JT, Hashimoto T, Saijo K. Chem—Eur J 1999;5(9):2740-9.

[112] Berman A, Hanson J, Leiserowitz L, Koetzle TF, Weiner S, Addadi L. Science 1993;259(5096):776-9.

[113] Berman A, Addadi L, Weiner S. Nature 1988;331(6156): $546-8$.

[114] Berman A, Addadi L, Kvick A, Leiserowitz L, Nelson M, Weiner S. Science 1990;250(4981):664-7.

[115] Frisch HL, Mark JE. Chem Mater 1996;8(8):1735-8.

[116] Ghadiri MR, Granja JR, Milligan RA, Mcree DE, Khazanovich N. Nature 1993;366(6453):324-7.

[117] Ghadiri MR, Granja JR, Buehler LK. Nature 1994; 369(6478):301-4.

[118] Ghadiri MR, Granja JR, Milligan RA, Mcree DE, Khazanovich N. Nature 1994;372(6507):709.

[119] Baral S, Schoen P. Chem Mater 1993;5(2):145-7.

[120] Archibald DD, Mann S. Nature 1993;364(6436):430-3.

[121] Shenton W, Pum D, Sleytr UB, Mann S. Nature 1997; 389(6651):585-7.

[122] Matsui H, Pan S, Douberly GE. J Phys Chem B 2001;105(9): 1683-6.

[123] Candau F. Microemulsion polymerization. In: Asua JM, editor. Polymeric dispersions: principles and applications. Dordrecht: Kluwer Academic Publishers; 1997.

[124] Yue J, Cohen RE. Supramol Sci 1994;1(2):117-22.

[125] Kane RS, Cohen RE, Silbey R. Chem Mater 1996;8(8): 1919-24.

[126] Zhang LF, Eisenberg A. Science 1995;268(5218):1728-31.

[127] Zhang LF, Eisenberg A. Polym Adv Technol 1998;9(10/11): 677-99.

[128] Chu B. Langmuir 1995;11(2):414-21.

[129] Mössmer S, Spatz JP, Möller M, Aberle T, Schmidt J, Burchard W. Macromolecules 2000;33(13):4791-8.

[130] Smith RC, Fischer WM, Gin DL. J Am Chem Soc 1997; 119(17):4092-3.

[131] Gray DH, Gin DL. Chem Mater 1998;10(7):1827-32.

[132] Deng H, Gin DL, Smith RC. J Am Chem Soc 1998;120(14): 3522-3.

[133] Menon VP, Lei JT, Martin CR. Chem Mater 1996;8(9): 2382-90.

[134] Lee H-K, Lee H, Ko YH, Chang YJ, Oh NK, Zin WC, Kim K. Angew Chem, Int Ed 2001;40(14):2669-71.

[135] Meier W, Hotz J, Günther-Ausborn S. Langmuir 1996; 12(21):5028-32.

[136] Hotz J, Meier W. Langmuir 1998;14(5):1031-6.

[137] Hotz J, Meier W. Adv Mater 1998;10(16):1387.

[138] Mckelvey CA, Kaler EW, Zasadzinski JA, Coldren B, Jung HT. Langmuir 2000;16(22):8285-90.

[139] Meier W. Langmuir 1996;12(5):1188-92.

[140] Meier W, Falk A, Odenwald M, Stieber F. Colloid Polym Sci 1996;274(3):218-26.

[141] Meier W. Langmuir 1996;12(26):6341-5.

[142] Meier W. Colloid Polym Sci 1997;275(6):530-6. 
[143] Meier W. Macromolecules 1998;31(7):2212-7.

[144] Meier W, Ramsden JJ. J Phys Chem 1996;100(5):1435-8.

[145] Schwarzwalder C, Meier W. Macromolecules 1997;30(16): 4601-7.

[146] Zhong ZY, Yin YD, Gates B, Xia YN. Adv Mater 2000; 12(3):206.

[147] Velev OD, Tessier PM, Lenhoff AM, Kaler EW. Nature 1999;401(6753):548.

[148] Caruso F, Spasova M, Susha A, Giersig M, Caruso RA. Chem Mater 2001;13(1):109-16.

[149] Decher G. Science 1997;277(5330):1232-7.

[150] Caruso F. Chem-Eur J 2000;6(3):413-9.

[151] Lakshmi BB, Dorhout PK, Martin CR. Chem Mater 1997; 9(3):857-62.

[152] Cepak VM, Hulteen JC, Che GL, Jirage KB, Lakshmi BB, Fisher ER, Martin CR. J Mater Res 1998;13(11):3070-80.

[153] Smarsly B, Polarz S, Antonietti M. J Phys Chem B 2001; 105(43):10473-83.

[154] Ozin GA. Adv Mater 1992;4(10):612-49.

[155] Whitney TM, Jiang JS, Searson PC, Chien CL. Science 1993; 261(5126):1316-9.

[156] Martin CR. Science 1994;266(5193):1961-6.

[157] Cepak VM, Hulteen JC, Che GL, Jirage KB, Lakshmi BB, Fisher ER, Martin CR, Yoneyama H. Chem Mater 1997;9(5): 1065.

[158] Piraux L, Dubois S, Demoustierchampagne S. Nucl Instrum Methods Phys Res, Sect B: Beam Interact Mater Atoms 1997;131(1-4):357-63.

[159] Martin CR, Mitchell DT. Template-synthesized nanomaterials in electrochemistry. Electroanalytical chemistry, vol. 21. New York: Marcel Dekker; 1999. pp. 1-74.

[160] Piraux L, Dubois S, Duvail JL, Radulescu A, Demoustier-
Champagne S, Ferain E, Legras R. J Mater Res 1999;14(7): 3042-50.

[161] Sapp SA, Mitchell DT, Martin CR. Chem Mater 1999;11(5): 1183.

[162] Esumi K, Suzuki A, Aihara N, Usui K, Torigoe K. Langmuir 1998;14(12):3157-9.

[163] Sooklal K, Hanus LH, Ploehn HJ, Murphy CJ. Adv Mater 1998;10(14):1083.

[164] Zhao MQ, Crooks RM. Angew Chem, Int Ed 1999;38(3): $364-6$.

[165] Tan NCB, Balogh L, Trevino SF, Tomalia DA, Lin JS. Polymer 1999;40(10):2537-45.

[166] Schaffer E, Thurn-Albrecht T, Russell TP, Steiner U. Nature 2000;403(6772):874-7.

[167] Thurn-Albrecht T, Schotter J, Kastle CA, Emley N, Shibauchi T, Krusin-Elbaum L, Guarini K, Black CT, Tuominen MT, Russell TP. Science 2000;290(5499): 2126-9.

[168] Xie Y, Qiao ZP, Chen M, Zhu YJ, Qian YT. Nanostruct Mater 1999;11(8):1165-9.

[169] Chen M, Xie Y, Qiao ZP, Zhu YJ, Qian YT. J Mater Chem 2000;10(2):329-32.

[170] Jiang X, Xie Y, Lu J, Zhu LY, He W, Qian YT. Chem Mater 2001;13(4):1213-8.

[171] Qi LM, Cölfen H, Antonietti M, Li M, Hopwood JD, Ashley AJ, Mann S. Chem-Eur J 2001;7(16):3526-32.

[172] Horn D, Rieger J. Angew Chem, Int Ed 2001;40(23): 4331-61.

[173] Liu T, Wan Q, Xie Y, Burger C, Liu LZ, Chu B. J Am Chem Soc 2001;123(44):10966-72.

[174] Müller A, Krickemeyer E, Bögge H, Schmidtmann M, Peters F. Angew Chem, Int Ed 1998;37(24):3360-3. 